\title{
Study on Complex Dynamics for the Waste Electrical and Electronic Equipment Recycling Activities Oligarchs Closed-loop Supply Chain
}

Meihong Zhu ( $\square$ Mhzhu200831@126.Com )

Tianjin University College of Management and Economics

Xiao Li

Tianjin university

Junhai Ma

Tianjin University of Commerce

Tiantong Xu

Tianjin University

Liqing Zhu

Tianjin University

\section{Research Article}

Keywords: Reverse chain, WEEE recycling, Game theory, Oligarchs ,Complex system, Closed-loop Supply Chain

Posted Date: June 14th, 2021

DOl: https://doi.org/10.21203/rs.3.rs-323727/v1

License: (1) This work is licensed under a Creative Commons Attribution 4.0 International License.

Read Full License

Version of Record: A version of this preprint was published at Environmental Science and Pollution Research on August 19th, 2021. See the published version at https://doi.org/10.1007/s11356-021-159799. 


\section{Study on Complex Dynamics for the Waste Electrical and} Electronic Equipment Recycling Activities Oligarchs

\section{Closed-loop Supply Chain}

Meihong $\mathrm{Zhu}^{1,2 *}$, Xiao $\mathrm{Li}^{1,2^{*}}$, Junhai $\mathrm{Ma}^{1}$, Tiantong $\mathrm{Xu}^{1}$, Liqing $\mathrm{Zhu}^{1}$

1. College of Management and Economics, Tianjin University, Tianjin 300072, China

2. Zhejiang University Of Water Resources And Electric Power , Zhejiang 310018 China

3. Meihong Zhu E-Mail: Mhzhu200831@126.Com;

4. Xiao Li E-Mail:xiaoli20180828@126.com;

5. Junhai Ma E-Mail: mjhtju@aliyun.com;

6. Tiantong Xu E-Mail: ttxu201608@126.com;

7. Liqing Zhu E-Mail:Lqzhu20080818@126.Com;

8. Ethics approval and consent to participate: Not applicable.

9. Consent for publication: Not applicable.

10. Availability of data and materials: Not applicable.

11. Competing interests: The authors declare that they have no competing interests.

12. Funding: The research was supported by the National Natural Science Foundation of China (No:71571131)

13. Authors' contributions:

14. Author contribution Meihong Zhu: Project administration and modeling

15. Xiao Li : Formal analysis, writing the original, methodology.reviewing, and preparing final draft.

16. Junhai Ma: Supervision, project administration and modeling

17. Tiantong $\mathrm{Xu}$ : Investigation, validation, writing and review and editing.

18. Liqing Zhu : modeling, validation, writing and review and editing.

19. Acknowledgements: We thank the reviewers for their careful reading and helpful comments on the revision of paper. This work was supported by the National Natural Science Foundation of China (grant number 71571131).

\footnotetext{
Abstract

Nowadays, with more and more WEEE (Waste Electrical and Electronic Equipment) being abandoned, WEEE recycling activities are increasingly popular. In this paper, we build a closed-loop supply chain model and focus on the recycling behaviors of the members in this supply chain, which contains two manufacturers, the retailer and the consumer. In the reverse chain, we set up dual channels and design two recycling methods: sell-back method and trade-in method. We use classical backward induction to run the model. And then we analyze the stability of the system and the impacts of some essential parameters by numerical simulation. The speed of
} 
the manufacture's decision adjustment has a significant effect on the stability of the model. When the decision variables of manufacturers go into instability, the profits of both manufacturers and the retailer have a profit loss in multiple cycles on average. The lower production cost of manufacturer 1 will increase the retailer's profit and self-profit, while manufacturer 2's profit will decrease. And the smaller price coefficient of the retailer can bring higher profits but aggravate the chaotic condition, and the stability of the whole system will decrease. In the end, we adopt the parameter control method and the decision-making method to control chaos, and they both have a good control effect.

Keywords: Reverse chain, WEEE recycling, Game theory, Oligarchs ,Complex system, Closed-loop Supply Chain

\section{Introduction}

An increasing number of states pay more attention to environmental issues including climate change, air pollution, and breakage of land, etc. Many corporations need a more stable and sustainable business model. It is the requirement for environmental consequences, social factors, and economic constraints. The generally accepted concept of "e-waste" is discarded electrical or electronic devices, such as common household appliances the recovery of mobile phones, washing machines, televisions, air conditioners computers (Guo et al. 2018). Recovery of WEEE (waste electrical and electronic equipment) products has become a hot issue in the economic field. Compared with the recycling of traditional materials, WEEE products are composed of more complicated material and components (Gu et al. 2017).

With the increasingly frequent update and upgrade of electrical and electronic equipment, the trade of related products rises and a great deal of electrical and electronic equipment is abandoned every day. Regulatory control of re-using, recycling, and recovery of electrical and electronic waste materials has been promulgated. (Ministry of Environment and Urbanization, 2012). In the EU, the amount of WEEE has been increasing by 3-5\% per year. In 2012 the electrical waste sums up to 3.6 billion $\mathrm{kg}$, of which over 70\% was recycled (Zlamparet et al., 2017). In China, according to the calculated theoretical scrap amount of waste electrical and electronic products, the theoretical scrap amount of 14 products in "The Disposal 
Catalogue of Waste Electrical and Electronic Products" in 2017 is shown in Table 1(White paper WEEE recycling industry in China 2017.). Among them, the theoretical scrap quantity of the first batch of products is about 100 million, including 3.216 million TV sets, 2.439 million refrigerators, 16.2 million washing machines, and 27.23 million room air conditioners. Compared with 2016, the theoretical scrap volume of the first batch of products presents an overall upward trend. ${ }^{1}$ For this reason, WEEE recycling activities have become an extensively researched issue in recent years.

Table 1. The theoretical scrap amount of China Electric \& Electronic Products in $2017^{1}$

\begin{tabular}{|l|l|l|l|}
\hline $\begin{array}{l}\text { Electric \& Electronic } \\
\text { Products }\end{array}$ & $\begin{array}{l}\text { Scrap amount } \\
\text { (million) }\end{array}$ & $\begin{array}{l}\text { Electric \& } \\
\text { Electronic Products }\end{array}$ & $\begin{array}{l}\text { scrap amount } \\
\text { (million) }\end{array}$ \\
\hline TV & 32.16 & Gas water heater & 9.33 \\
\hline Refrigerator & 24.39 & Printer & 30.99 \\
\hline washing machine & 16.20 & Copier & 6.69 \\
\hline Air conditioner & 27.23 & Fax machine & 5.06 \\
\hline Micro-computer & 25.24 & Fixed telephone & 23.80 \\
\hline Oil absorption & 39.87 & Mobile phone & 232.75 \\
\hline Electric water heater & 25.85 & Monitors & 0.48 \\
\hline
\end{tabular}

To investigate how WEEE recycling activities affect the oligarch's closed-loop supply chain, a method that has dual channels sales and two recycling is designed.

Based on observations from current literature and actual situation, our model's innovation can be summarized as follows.

(1) We build a closed-loop supply chain including two manufacturers and one retailer. Two different recovery modes are taken into account. It can be expanded by applying other models from literature in the future.

(2) We consider competition between two different recycling methods in the waste recycling market. Besides, based on Complex System Theory, we adopt a dynamic decision-making method instead of a single period of static decision-making.

(3) Chaos is controlled by adjusting the means of relevant parameters and decision-making methods.

The contribution of this paper is to enrich the analytical analysis on CLSC, investigate the complexity of the decision-making process, and inspire the operations method in recycling activities.

Based on the above background, this paper tries to discuss the following research questions: 
(1) How is the complex chaotic dynamical process in the reverse channel structure?

(2) How to control and coordinate the WEEE recycling activities under the closed-loop supply chain structures?

The rest of this paper is organized as follows. In section 2, we describe the problem, show symbols and assumptions, and a closed-loop supply chain network which is composed of two manufacturers and one retailer. We solve the model and analyze the local stability in section 3. And then we further analyze the influence of parameters on the model's stability in section 4. Based on what we have stated, we introduce the method to control the chaos system in section 5. Finally, we make conclusions in section 6 .

\section{Literature Review}

WEEE is composed of lots of complex devices and components. Proper disposal of WEEE not only reduces environmental pollution but also enhances resource utilization efficiency which benefits manufacturers as well as the environment. For this reason, product recycling activities have been paid attention to around the world (Lu et al., 2018; Polat et al., 2018). We take China as an example since the Chinese government puts great emphasis on WEEE recycling activities. A model of green design, green production, green sales, green recycling, and disposal led by production enterprises is emerging now. ${ }^{1}$ Under great pressure from the government, other firms and consumers are responsible for environmental and social as well, manufacturers would choose to recycle used products. For example, HUAWEI is collecting used products through VWALL; Changhong and Haier are also actively building green recycling systems for used products. Meanwhile, retailers such as SuNing, JingDong, also participate in collecting used products activities.

The recycling process leads to better economic viability and environmental sustainability which makes the closed-loop supply chain more attractive. (Hong et al., 2017). The closed-loop supply chain contains the forward logistics and reverses logistics. In forward logistics, the supply chain process includes purchasing, manufacturing, and selling; in reverse logistics, the supply chain differs from traditional supply chain realizes recycle and remanufacture, is designed to increase the utilization ratio of raw materials, reduce pollution emissions to protect the environment and lower costs at the same time. Therefore, constructing a closed-loop 
supply chain can promote sustainable development. The recycling activity has become a new trend in logistics and supply chain management. Based on related research in the closed-loop supply chain and reverse supply chain, the collector recycling used products in the closed-loop supply chain can be classified into three categories: manufacturer, retailer, and the third-party (Savaskan et al, 2004).

A great number of researches about WEEE recycling has been done in recent years. Xu et al. (2017) investigated the design of a global reverse supply chain. The results show the effect of uncertainties and carbon constraints on decisions to reduce costs and emissions. Bal and Satoglu (2018) investigated a multi-facility, multi-product, and multi-period model which collects WEEE products and recover the waste materials. Bing (2015) redesigned a reverse supply chain to provide useful insights for managing waste as a resource in the view of a global perspective. Liu et al. (2017) studied a manufacturer who owes a WEEE recycling qualification under fund policy and analyzed the effect of fund policy on the manufacturer. Liu et al. (2006) built a dual-channel WEEE recycling model that contains a formal section and informal section. They considered price competition based on quality and government subsidy, obtained the equilibrium prices as well as the influence of government subsidy under four competitive scenarios. Ma et al. (2020) constructed a closed-loop supply chain and studied how different channel power affect the dynamic characteristic of the system. In terms of competition in the reverse supply chain, most papers focus on competitions between two retailers, between two third parties, or between one retailer and one-third party. For example, Savaskan et al. (2006) studied two competitive retailers in 2006. Therefore, we consider the fact that some manufacturers recycle used products by themselves and build a dual-channel supply chain in which one manufacturer collects used products from consumers directly and the other manufacturer collects used products through retailers. Yin et al. (2010) discussed the effect of the retail used goods market and the electronic peer-to-peer (P2P) market on the primary market. Inspired by Yin et al. (2010), we set a trade-in recycling method where the retailer buys back a used product and sells a new one to consumers. Zhou et al. (2017) explored a two-period model in which a manufacturer sells products and two competitive recyclers recycle used products under Extended Producer Responsibility (EPR) and further discussed the decision about setting subsidy from the government. Based on current research, we further consider a three-period model while putting more emphasis on the reverse supply chain. 
Considering the situations that the buyers promise to buy back the unsold products from the seller, Xie et al (2020) studied the effect of income uncertainty and relative bargaining power on the performance of repurchase contracts in supply chain.

Analyzing product recycling activities, most literature focus on the closed-loop supply chain. Based on different strategies of collecting used products, Savaskan et al. (2004) analyzed three different reverse loops of the supply chain and analyzed the results. Östlin et al. (2008) focused on remanufacturing. They expanded seven different types of closed-loop supply chains and analyzed the advantages and disadvantages of each model. Qiang et al. (2013) built a closed-loop supply chain which contains raw material suppliers, retail outlets, and manufacturers, and gave the optimality conditions of the various decision-makers. Huang et al. (2013) explored the optimal strategies in the closed-loop supply chain with a dual recycling channel in which retailers and the third party collect used products. Giovanni et al. (2014) introduced a two-period closed-loop supply chain and analyzed whether to collect end-of-life products by remanufacturer exclusively or introduce a retailer or a third-service provider. Wei et al. (2015) analyzed a closed-loop supply chain under symmetric and asymmetric information. Gao et al. (2016) focused on exploring power structures' effect on optimal strategies in a closed-loop supply chain. In a word, for the reverse channel in the closed-loop supply chain, most literature focus on the method of collection, power structure, and so on. At present, competition between two different recycling methods in the waste recycling market is less mentioned. Consequently, based on Guo and Ma (2013) and Ma et al. (2013) and associated with reality, we enter into discussion in the two different recycling methods in a closed-loop supply chain and expect to make some useful supplements on this. Besides, most literature base on two hypotheses: complete information and "completely rational person" hypothesis. Actually, in the long run, players would adjust their decisions according to the information they received. Despite that, there is a lot of literature with WEEE recycling activities, the study of complexity theory is not widely in the current literature. Thus, we introduce dynamic game when analyzing the closed-loop supply chain in the light of Ma and Guo (2014) in which they introduced dynamic system concepts to simulate the evolution of the strategic decisions over multiple periods. Tian et al. (2020) analyze the complexity of a multi-channel supply chain and reveled that a larger adjustment speed of the sale effort causes the unstable state of the system. Based on bounded rationality, Ma et al. 
(2020) explored the impact of decision sequence on the profits of the enterprise and how the adjustment speed affect the stability of the system. Considering a supply chain with two different manufacturers who produce fuel vehicle and battery vehicle respectively, Bao et al. (2020) derived the optimal decisions and make comparative analysis between three different games, finding that the adjustment speed of the ecofriendly level has the greatest impact on the market.

\section{Methodology}

During the last four decades, nonlinear dynamics have made great progress and have attracted increasing attention from different fields including supply chain management. Ma and $\mathrm{Wu}$ (2014) explored a discrete triopoly dynamical model and analyzed the complexity of this system. Elsadany (2010) proposed and analyzed a duopoly delayed bounded rationality game and the analysis proved that delayed bounded rationality contributed to the higher possibility of Nash equilibrium point. Du et al (2013) analyzed a dynamic duopoly game with heterogeneous players. They found the chaos was harmful to at least one player of the two, and an appropriate limiter would be conducive to the players' performance. As an essential tool, the dynamic game also has been applied to the reverse supply chain. Xie and Ma (2016) researched a Duopoly market of color TV recycling, analyzed the influence of coefficients changing on the system's stability, and introduced the method of chaos control. Ma and Wang (2014) first built a closed-loop supply chain in which the retailer sells and collects products and the manufacturer produces and recovers products and then presents the dynamic phenomena.

\subsection{Model Framework}

In this paper, we consider a two-period model, but we focus on the recycling behavior of the members in a typical supply chain including two manufacturers, one retailer and consumers. In the forward chain, two manufacturers sell their products to the retailer and the retailer sells products to consumers. In the reverse chain, we set up dual channels and design two recycling methods: sell-back method and trade-in method. Consumers sell the used product back to the retailer utilizing the sell-back recycling or trade the used product in for a new one through trade-in recycling. When using the method of sell-back, consumers can get money by selling waste products. When using the method of trade-in, consumers can sell back waste products to the retailer in exchange for lower prices of new products. And then the retailer sells the used products back to manufacturer 1. Meanwhile, consumers are allowed to sell used 
products to manufacturer 2 directly. In the next stage, manufacturer 1 and manufacturer 2 remanufacture used products and sell new products to consumers. Our model in this paper is shown in Fig. 1.

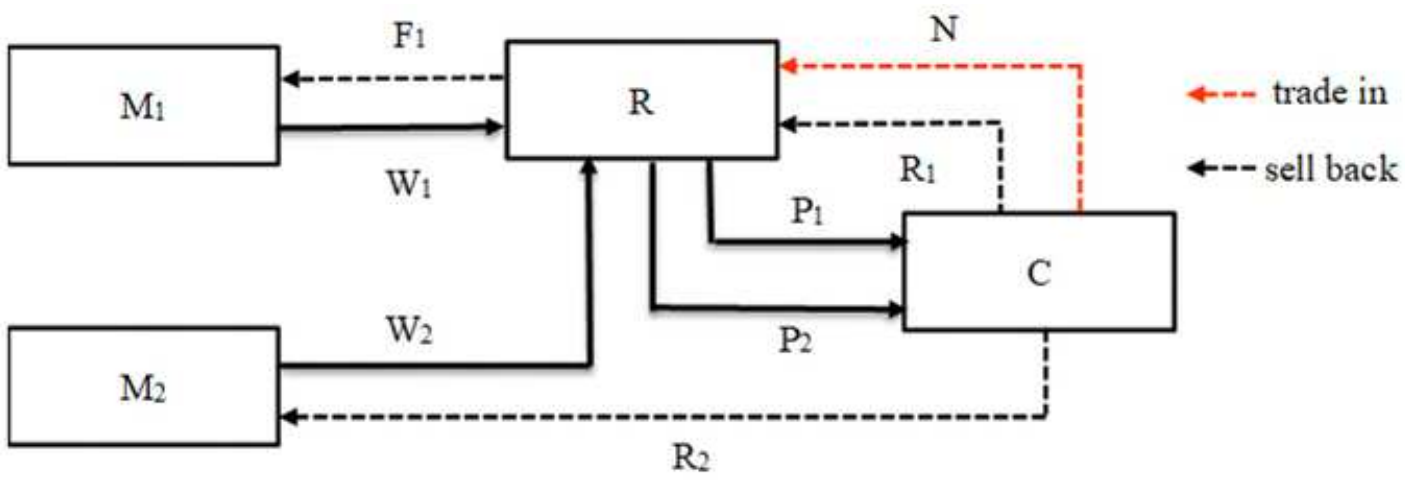

Fig. 1. Recycling Supply Chain Model

In Fig.1, M1 represents manufacturer 1 and in the same way, M2 shows manufacturer 2. $\mathrm{R}$ represents the retailer. And $\mathrm{C}$ is the consumer.

\subsection{Symbols and Assumptions}

The relevant symbols are as follows.

$\mathrm{Q}_{\mathrm{i}}$ demand for the product $\mathrm{i}$.

$a_{i}$ basic market size of product $i$.

$b_{i}$ sensitivity of consumers to the retail price of product $i$.

$d_{i}$ sensitivity of consumers to the rival products' retail price of product $i$.

Pi unit retail price of product $i$.

Wi unit wholesale price of product $i$.

$Q_{\text {ri }}$ recycling quantity of product $i$.

$\mathrm{N}$ difference between the sell-back price and the trade-in price.

$\mathrm{g}_{\mathrm{i}}$ sensitivity of consumers to the sell-back price of product $i$.

$h_{i}$ sensitivity of consumers to the rival products' sell-back price of product $i$.

$\mathrm{t}_{1}$ sensitivity of the difference between the sell-back price and the trade-in price.

$\mathrm{F}_{1}$ sell-back price of manufacturer 1 .

$\mathrm{R}_{1}$ sell-back price of the retailer.

$\mathrm{R}_{2}$ sell-back price of manufacturer 2 .

$\mathrm{C}_{\mathrm{i}}$ cost of product $\mathrm{i}$.

Q $\varepsilon$ trade-in quantity.

$\mathrm{C}_{\mathrm{ri}}$ cost of product i made from the used product.

$\Pi_{i}$ the profit of manufacturer i.

$\Pi_{\mathrm{R}}$ retailer's profit

$\lambda_{3}$ price coefficient of retailer

$\mathrm{k}_{\mathrm{i}}$ potential maximum waste quantity of product $\mathrm{i}$ for recycling in the market $\mathrm{v}_{\mathrm{i}}(\mathrm{i}=1,2,3)$ indicate the adjusting speed of $\mathrm{F}_{1}, \mathrm{R}_{2}$, and $\mathrm{N}$ respectively. To simplify the analysis, we made those assumptions as follows. 
(a) The manufacturer and retailer are bounded rational.

(b) Remanufactured products are exactly the same as new products.

(c) The transportation cost and other expenses are not taken into account.

(d) The demand is linearly dependent on price.

(e) The recycling quantity is linearly dependent on the recycling price.

\subsection{Model Construction}

In our model, manufacturer 1 produces product1, and manufacturer 2 produces product2. Those two products are made of the same raw materials, possess the same function, quality, and price et cetera. We assumed that the demand is linearly dependent on price. Meanwhile, the rival product's retail price also affects demand. Thus, the demand for new product 1 and new product 2 can be given as follows.

$$
\left\{\begin{array}{l}
Q_{1}=a_{1}-b_{1} P_{1}+d_{1} P_{2}=a_{1}-b_{1}\left(1+\lambda_{3}\right) W_{1}+d_{1}\left(1+\lambda_{3}\right) W_{2} \\
Q_{2}=a_{2}-b_{2} P_{2}+d_{2} P_{1}=a_{2}-b_{2}\left(1+\lambda_{3}\right) W_{2}+d_{2}\left(1+\lambda_{3}\right) W_{1}
\end{array}\right.
$$

Comparably, we set the recycling quantity linearly depending on the recycling price. So the sell-back quantity of used products for the retailer and the sell-back quantity of used products for manufacturer 2 can be given as follows.

$$
\left\{\begin{array}{l}
Q_{r 1}=k_{1}+g_{1} R_{1}-h_{1} R_{2}-t_{1} N=k_{1}+g_{1} F_{1}\left(1-\lambda_{3}\right)-h_{1} R_{2}-t_{1} N \\
Q_{r 2}=k_{2}+g_{2} R_{2}-h_{2} R_{1}-t_{1} N=k_{2}+g_{2} R_{2}-h_{2} F_{1}\left(1-\lambda_{3}\right)-t_{1} N
\end{array}\right.
$$

Similarly, the trade-in quantity can be given as follows.

$$
Q_{e}=\beta+\gamma N-t_{2}\left(R_{1}+R_{2}\right)=\beta+\gamma N-t_{2} F_{1}\left(1-\lambda_{3}\right)-t_{2} R_{2}
$$

In the set recycling supply chain, the profits of manufacturers include two parts: the profits of new products and the profits of used products. And the profits of the retailer come from selling and recycling products 1 and 2 . The profit model can be given as follows.

$$
\left\{\begin{array}{l}
\Pi_{1}=\left(W_{1}-C_{1}\right)\left(Q_{1}-Q_{e}-Q_{r 1}\right)+\left(W_{1}-C_{r 1}-F_{1}\right)\left(Q_{e}+Q_{r 1}\right) \\
\Pi_{2}=\left(W_{2}-C_{2}\right)\left(Q_{2}-Q_{r 2}\right)+\left(W_{2}-C_{r 2}-R_{2}\right) Q_{r 2} \\
\Pi_{r}=\left(P_{1}-W_{1}\right) Q_{1}+\left(F_{1}-R_{1}\right) Q_{r 1}+\left(F_{1}-R_{1}-N\right) Q_{e}+\left(P_{2}-W_{2}\right) Q_{2}
\end{array}\right.
$$

To maximize the profit, the three parties (manufacturer 1, manufacturer 2, and the retailer) have to make appropriate decisions. According to the profit model (4), the decision variable of manufacturer 1 is the sell-back price of manufacturer $1, F_{1}$, the decision variable of manufacturer 2 is the sell-back price of manufacturer $1, R_{2}$, and the decision variable of the retailer is the difference between the sell-back price and the trade-in price, $N$.

As to manufacturer 1, its profit can be written in the form

$$
\Pi_{1}=\left(W_{1}-C_{1}\right)\left(Q_{1}-Q_{e}-Q_{r 1}\right)+\left(W_{1}-C_{r 1}-F_{1}\right)\left(Q_{e}+Q_{r 1}\right)
$$

$$
=\left(W_{1}-C_{1}\right) Q_{1}+\left(C_{1}-C_{r}-F_{1}\right)\left(Q_{e}+Q_{r 1}\right)
$$

where 


$$
\frac{\partial\left(W_{1}-C_{1}\right) Q_{1}}{\partial F_{1}}=\frac{\partial\left(W_{1}-C_{1}\right) Q_{1}}{\partial R_{2}}=\frac{\partial\left(W_{1}-C_{1}\right) Q_{1}}{\partial N}=0
$$

300

301

302

303

304

305

306

307

308

309

310

311

312

313

314

321

Thus, $\left(W_{1}-C_{1}\right) Q_{1}$ it is independent of the three decision variables. To simplify the analysis, model (5) can be simplified as

$$
\Pi_{1}^{\prime}=\left(C_{1}-C_{r}-F_{1}\right)\left(Q_{e}+Q_{r 1}\right)
$$

As to manufacturer 2, its profit can be written in the form

$$
\Pi_{2}=\left(W_{2}-C_{2}\right)\left(Q_{2}-Q_{r 2}\right)+\left(W_{2}-C_{r 2}-R_{2}\right) Q_{r 2}
$$

$$
=\left(W_{2}-C_{2}\right) Q_{2}+\left(C_{2}-C_{r 2}-R_{2}\right) Q_{r 2}
$$

where

$$
\frac{\partial\left(W_{2}-C_{2}\right) Q_{2}}{\partial F_{1}}=\frac{\partial\left(W_{2}-C_{2}\right) Q_{2}}{\partial R_{2}}=\frac{\partial\left(W_{2}-C_{2}\right) Q_{2}}{\partial N}=0
$$

Comparably, $\left(W_{2}-C_{2}\right) Q_{2}$ is independent of the three decision variables. To simplify the analysis, the model (8) can be simplified as

$$
\Pi_{2}^{\prime}=\left(C_{2}-C_{r 2}-R_{2}\right) Q_{r 2}
$$

As to the retailer, its profit is given as

$$
\Pi_{r}=\left(P_{1}-W_{1}\right) Q_{1}+\left(F_{1}-R_{1}\right) Q_{r 1}+\left(F_{1}-R_{1}-N\right) Q_{e}+\left(P_{2}-W_{2}\right) Q_{2}
$$

Similarly, $\left(P_{1}-W_{1}\right) Q_{1},\left(P_{2}-W_{2}\right) Q_{2}$ is independent of the three decision variables. To simplify the analysis, the model (11) can be simplified as

$$
\Pi_{r}^{\prime}=\left(F_{1}-R_{1}\right) Q_{r 1}+\left(F_{1}-R_{1}-N\right) Q_{e}
$$

So the simplified profit model can be given as

$$
\left\{\begin{array}{l}
\Pi_{1}^{\prime}=\left(C_{1}-C_{r 1}-F_{1}\right)\left(Q_{e}+Q_{r 1}\right) \\
\Pi_{2}^{\prime}=\left(C_{2}-C_{r 2}-R_{2}\right) Q_{r 2} \\
\Pi_{r}^{\prime}=\left(F_{1}-R_{1}\right) Q_{r 1}+\left(F_{1}-R_{1}-N\right) Q_{e}
\end{array}\right.
$$

For further simplification, if we set

$$
\left\{\begin{array}{l}
C_{1}-C_{r 1}=d C_{1} \\
C_{2}-C_{r 2}=d C_{2}
\end{array}\right.
$$

then the model (13) can be written in the form

$$
\left\{\begin{array}{l}
\Pi_{1}^{\prime}=\left(d C_{1}-F_{1}\right)\left(Q_{e}+Q_{r 1}\right) \\
\Pi_{2}{ }^{\prime}=\left(d C_{2}-R_{2}\right) Q_{r 2} \\
\Pi_{r}{ }^{\prime}=\left(F_{1}-R_{1}\right) Q_{r 1}+\left(F_{1}-R_{1}-N\right) Q_{e}
\end{array}\right.
$$




\section{Results and Discussion}

\subsection{Model Analysis}

Our model mainly involves three parties, and they all have their own decision variable. To maximize the profit, they will adjust the value of decision variables in the game. We first consider the retailer's decision. The derivative of the retailer's profit model with respect to $N$ is given as

$$
\frac{\partial \Pi_{r}^{\prime}}{\partial N}=R_{2} t_{2}-t_{1}\left(F_{1}+F_{1}\left(\lambda_{3}-1\right)\right)-\gamma n-\beta+\gamma\left(F_{1}-n+F_{1}\left(\lambda_{3}-1\right)\right)-F_{1} t_{2}\left(\lambda_{3}-1\right)
$$

We set equation (16) equals to zero. Then we can get the optimal decision of retailer

$$
N^{*}=\frac{-\left(\beta-F_{1} t_{2}-R_{2} t_{2}-F_{1} \gamma \lambda_{3}+F_{1} \lambda_{3} t_{1}+F_{1} \lambda_{3} t_{2}\right)}{2 \gamma}
$$

Substituting the optimal decision of retailer $N^{*}$ into manufacturers profit models, we get the manufacturers profit models to the retailer's decision

$$
\left\{\begin{aligned}
\Pi_{1}^{\prime}= & \left(d C_{1}-F_{1}\right)\left(\frac{\beta}{2}+k_{1}+\frac{F_{1} t_{2}}{2}-h_{1} R_{2}-\frac{R_{2} t_{2}}{2}+F_{1} t_{2}\left(\lambda_{3}-1\right)+\frac{F_{1} \gamma \lambda_{3}}{2}-\frac{F_{1} \lambda_{3} t_{1}}{2}\right. \\
& \left.-\frac{F_{1} \lambda_{3} t_{1}}{2}+\frac{t_{1}\left(b-F_{1} t_{2}-R_{2} t_{2}-F_{1} \gamma \lambda_{3}+F_{1} \lambda_{3} t_{1}+F_{1} \lambda_{3} t_{2}\right)}{2 \gamma}-F_{1} g_{1}\left(\lambda_{3}-1\right)\right) \\
\Pi_{2}^{\prime}= & \left(d C_{2}-R_{2}\right)\left(k_{2}+g_{2} R_{2}+\frac{t_{1}\left(\beta-F_{1} t_{2}-R_{2} t_{2}-F_{1} \gamma \lambda_{3}+F_{1} \lambda_{3} t_{1}+F_{1} \lambda_{3} t_{2}\right)}{2 \gamma}\right. \\
& \left.+F_{1} h_{2}\left(\lambda_{3}-1\right)\right)
\end{aligned}\right.
$$

The derivatives of the manufacturers' profit models are given as

$$
\left\{\begin{aligned}
\frac{\partial \Pi_{1}^{\prime}}{\partial F_{1}} & =h_{1} R_{2}-k_{1}-\left(d C_{1}-F_{1}\right)\left(\frac{\lambda_{3} t_{1}}{2}-\frac{\gamma \lambda_{3}}{2}-\frac{t_{2}}{2}+\frac{\lambda_{3} t_{2}}{2}+g_{1}\left(\lambda_{3}-1\right)\right. \\
& \left.-t_{2}\left(\lambda_{3}-1\right)+\frac{t_{1}\left(t_{2}+\gamma \lambda_{3}-\lambda_{3} t_{1}-\lambda_{3} t_{2}\right)}{2 \gamma}\right)-\frac{F_{1} t_{2}}{2}-\frac{\beta}{2}+\frac{R_{2} t_{2}}{2}-F_{1} t_{2}\left(\lambda_{3}-1\right) \\
& -\frac{F_{1} \gamma \lambda_{3}}{2}+\frac{F_{1} \lambda_{3} t_{1}}{2}+\frac{F_{1} \lambda_{3} t_{2}}{2} \\
& -\frac{t_{1}\left(t_{1}\left(b-F_{1} t_{2}-R_{2} t_{2}-F_{1} \gamma \lambda_{3}+F_{1} \lambda_{3} t_{1}+F_{1} \lambda_{3} t_{2}\right)\right)}{2 \gamma}+F_{1} g_{1}\left(\lambda_{3}-1\right) \\
\frac{\partial \Pi_{2}^{\prime}}{\partial R_{2}} & =\left(d C_{2}-R_{2}\right)\left(g_{2}-\frac{t_{1} t_{2}}{2 \gamma}\right)-g_{2} R_{2}-k_{2}- \\
& \frac{t_{1}\left(\beta-F_{1} t_{2}-R_{2} t_{2}-F_{1} \gamma \lambda_{3}+F_{1} \lambda_{3} t_{1}+F_{1} \lambda_{3} t_{2}\right)}{2 \gamma}-F_{1} h_{2}\left(\lambda_{3}-1\right)
\end{aligned}\right.
$$

In our model, manufacturers are of bounded rationality and they play the leading roles. And the retailer makes decisions following the manufacturers. So the evolution game model for the three parties is given as 


$$
\left\{\begin{array}{l}
F_{1}(t+1)=F_{1}(t)+v_{1} F_{1}(t) \frac{\partial \Pi_{1}^{\prime}}{\partial F_{1}} \\
R_{2}(t+1)=R_{2}(t)+v_{2} R_{2}(t) \frac{\partial \Pi_{2}^{\prime}}{\partial R_{2}} \\
N(t+1)=N(t)+v_{3}\left(N(t)^{*}-N(t)\right)
\end{array}\right.
$$

\section{Proposition 1}

The Nash equilibrium of the game, $\left(F_{1}^{*}, R_{2}^{*}, N^{*}\right)$, could be derived by solving the equations of $\frac{\partial \Pi_{1}^{\prime}}{\partial F_{1}}=0, \frac{\partial \Pi_{2}^{\prime}}{\partial R_{2}}=0$

\section{Proposition 2}

For the optimal trade in strategy, we can observe that:

1. The trade in price will ramp up with the increasing of sell-back price of manufacturer 1 when $t_{2}+\lambda_{3}\left(\gamma-t_{1}-t_{2}\right)>0$;

2. The trade in price will ramp up with the increasing of sell-back price of manufacturer 1 when $t_{2}+\lambda_{3}\left(\gamma-t_{1}-t_{2}\right)<0$;

3. The trade in price will definitely ramp up with the increasing of sell-back price of manufacturer 2 .

Proof: It can be obtained that $\frac{\partial N^{*}}{\partial F_{1}}=\frac{t_{2}+\lambda_{3}\left(\gamma-t_{1}-t_{2}\right)}{2 \gamma}$. Hence, the first and the second lemma are easily proved by figuring out the inequation of $\frac{\partial N^{*}}{\partial F_{1}}>0$ and $\frac{\partial N^{*}}{\partial F_{1}}<0$. Additionally, we can obtain that $\frac{\partial N^{*}}{\partial R_{2}}=\frac{t_{2}}{2 \gamma}$, which can generate the third lemma of Proposition 2.

From Proposition1, we can know that that if manufacturer 2 sets a higher sell-back price, the trade in price will be increased. This finding reveals the competition of recycling between the retailer and the manufacture 2 - a player will increase the recycling price if his competitor set a more higher recycling price. That make sense in practice. 


\subsection{Inherent Complexity Analysis}

First, a numerical simulation has been done to do a pre-analysis for our model. We set parameters as

$$
\begin{aligned}
& k_{1}=0.5, k_{2}=0.5, g_{1}=1, g_{2}=1, h_{1}=0.3, h_{2}=0.3, \\
& \beta=0.3, \gamma=0.3, t_{2}=1, d C_{1}=2.5, d C_{2}=2.5, \lambda_{3}=0.2
\end{aligned}
$$

The dynamic changes of decision variables $F_{1}$ and $R_{2}$ from cycle 100 to cycle 200 are shown in Fig.2.

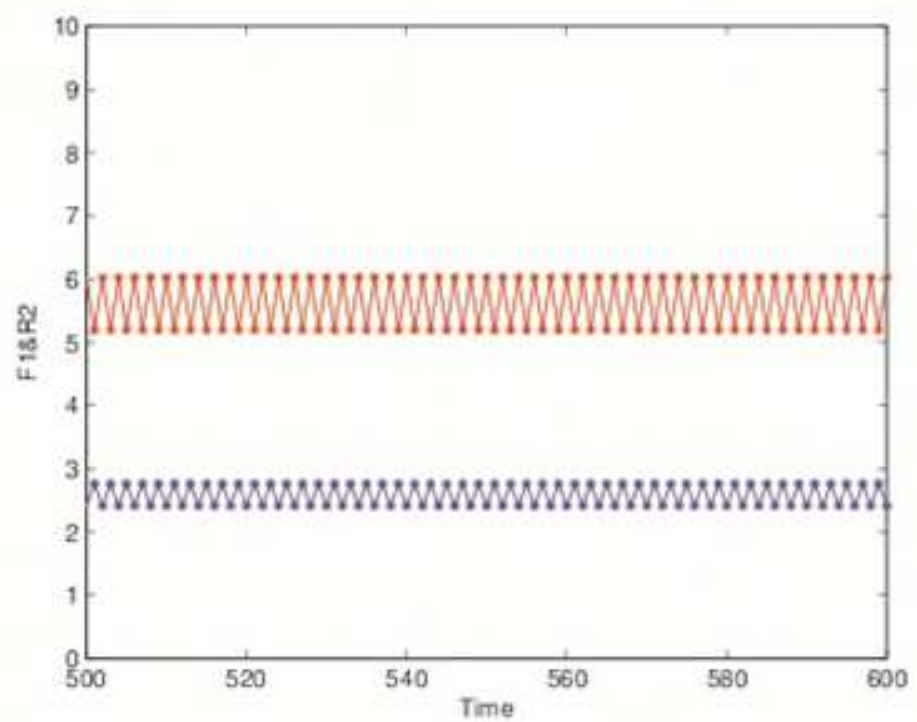

Fig. 2. Time Sequence Diagram

As shown in Fig.2, under the set parameters, the changes of decision variables are cyclical. The whole game is in an unstable state. Thus, we take a further analysis of the stability of the model.

The Jacobi matrix of the system can be given as

$$
J a c=\left[\begin{array}{ccc}
J_{11} & v_{1} F_{1}\left(h_{1}+\frac{t_{2}}{2}+\frac{t_{1} t_{2}}{2 \gamma}\right) & 0 \\
-v_{2} R_{2}\left(h_{2}\left(\lambda_{3}-1\right)+\frac{\left(t_{1}\left(\lambda_{3} t_{1}-\gamma \lambda_{3}+t_{2}\left(\lambda_{3}-1\right)\right)\right)}{2 \gamma}\right) & J_{22} & 0 \\
\frac{-\left(v_{3}\left(\lambda_{3} t_{1}-\gamma \lambda_{3}+t_{2}\left(\lambda_{3}-1\right)\right)\right)}{2 \gamma} & \frac{v_{3} t_{2}}{2 \gamma} & 1-v_{3}
\end{array}\right]
$$

According to the Jury criterion, the stability of the discrete dynamic system relates to whether the eigenvalues are in the unit circle. The eigenvalues of the model can be written as 


$$
\begin{aligned}
& |J a c-\lambda E| \\
& =\left|\begin{array}{cc}
J_{11}-\lambda_{1} & v_{1} F_{1}\left(h_{1}+\frac{t_{2}}{2}+\frac{t_{1} t_{2}}{2 \gamma}\right) \\
-v_{2} R_{2}\left(h_{2}\left(\lambda_{3}-1\right)+\frac{\left(t_{1}\left(\lambda_{3} t_{1}-\gamma \lambda_{3}+t_{2}\left(\lambda_{3}-1\right)\right)\right)}{2 \gamma}\right) & J_{22}-\lambda_{2}
\end{array}\right|\left|1-v_{3}-\lambda_{3}\right| \\
& \Rightarrow \lambda_{3}=1-v_{3}
\end{aligned}
$$

381

382

383

384

385

386

387

388

389

390

391

392

393

394

395

396

397

\section{Proposition 3}

The dynamic system will be stable if the adjustment speed of the retailer is in the range of $v_{3} \in[0,2]$.

Proof According to equation (22), if $v_{3} \in[0,2]$, then $\lambda_{3} \in[-1,1]$. In such a condition, the third eigenvalue is in the unit circle.

Proposition 3 indicates that if the retailer adjusts his trade in speed in a not so high speed, the dynamic system will not trapped into unstable state accordingly. Hence, the stability of the model is related to manufacturers' decisions.

Then, we further analyze the influence of the decision adjustment speed of manufacturer 1 and manufacturer 2 on the stability of the game. We set the decision adjustment speed of manufacturer $1 v_{1}$ as a variable and the decision adjustment speed of manufacturer 2 as $v_{2}=0.1$ and $v_{2}=0.3$. The results of numerical simulation are shown in Fig.3 and Fig.4.

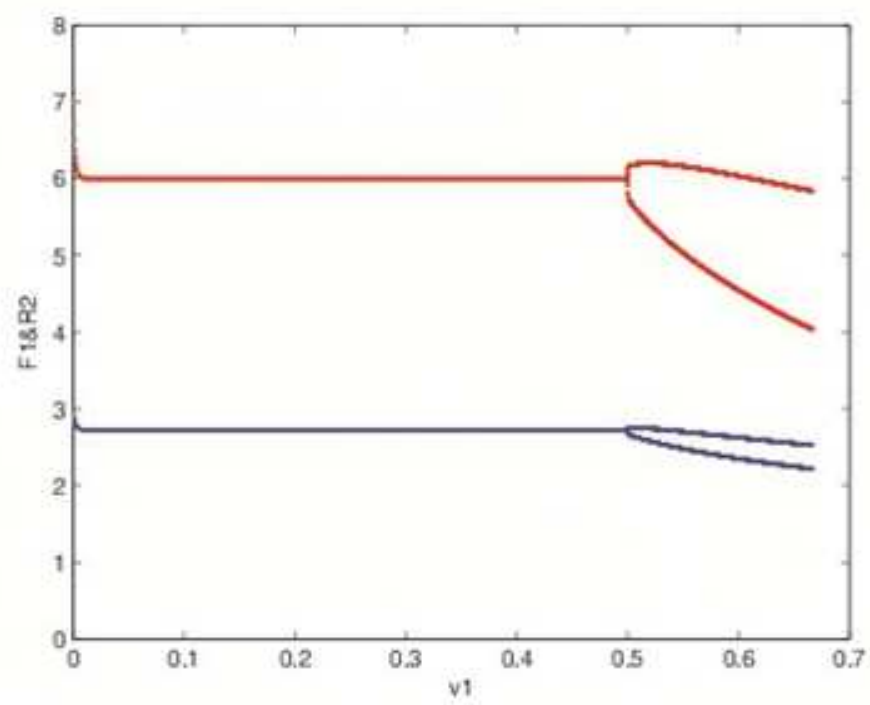

Fig. 3. Bifurcation diagram when $v_{2}=0.1$ 
398

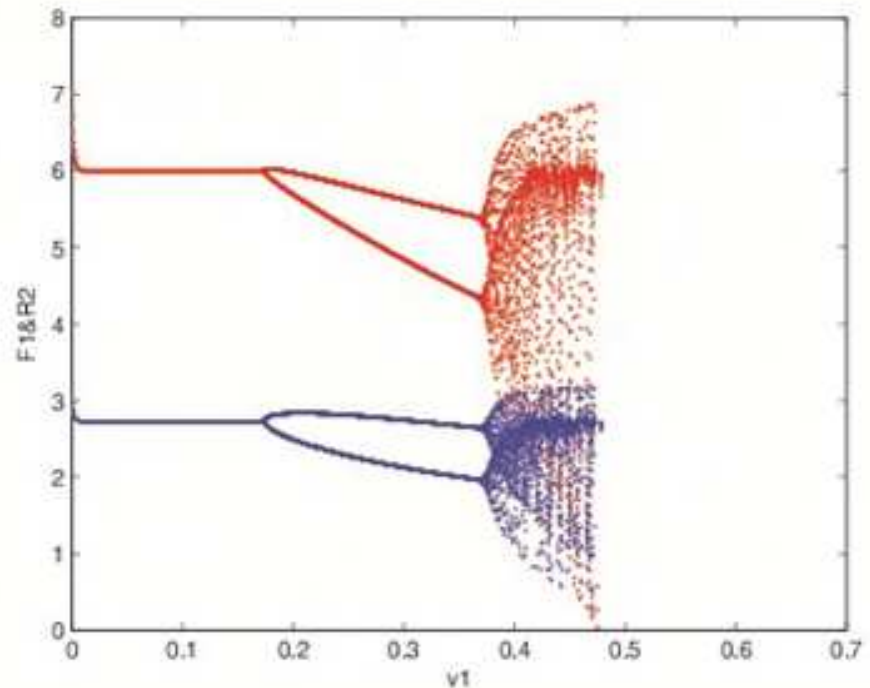

Fig. 4. Bifurcation diagram when $v_{2}=0.3$

The results show that with the increase of the decision adjustment speed of manufacturer 1, the decision variables of manufacturer 1 and manufacturer 2 go from a stable state into chaos. Besides, the decision adjustment speed of manufacturer 2 has a significant impact on the decision variables.

Next, we set the decision adjustment speed of manufacturer $2 v_{2}$ as a variable and the decision adjustment speed of manufacturer 1 as $v_{1}=0.1$ and $v_{1}=0.5$. The results of numerical simulation are shown as Fig.5 and Fig.6.

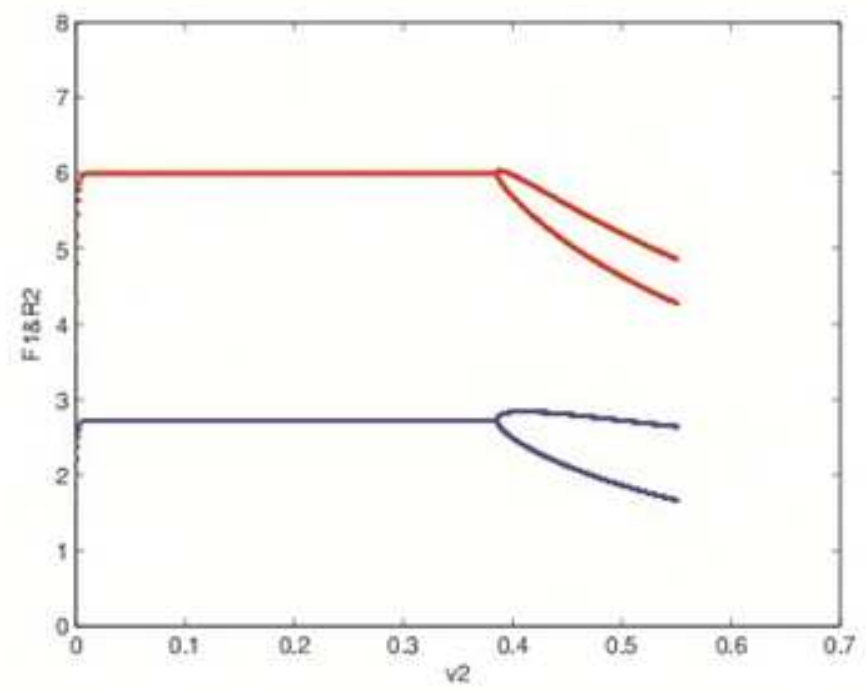

Fig. 5. Bifurcation diagram when $v_{1}=0.1$ 


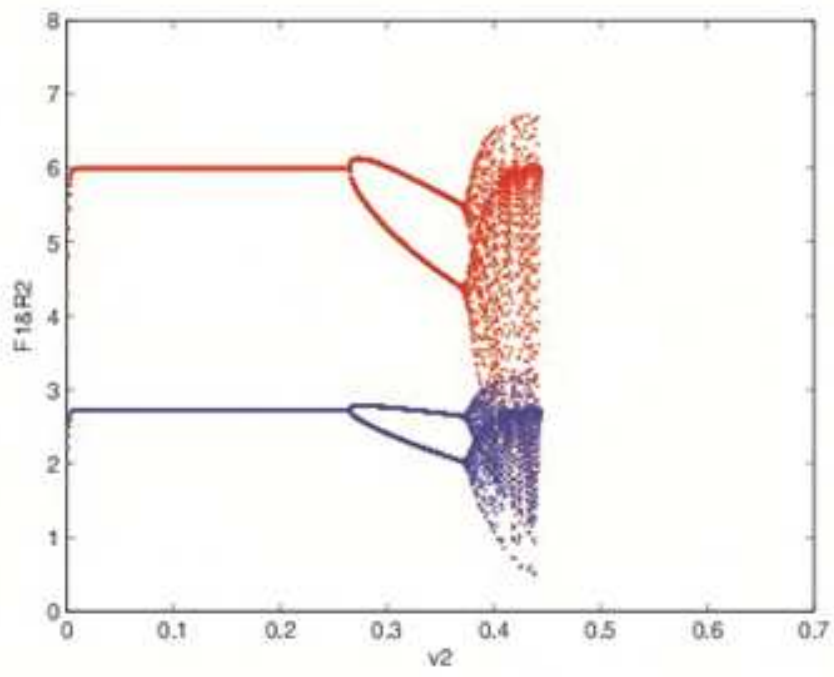

410

Fig. 6. Bifurcation diagram when $v_{1}=0.5$

According to the results, the trends of the change of the decision variables are similar to those of the previous numerical simulation, which also go from a stable state into chaos. Hence, we can get the conclusion that the stability of the game is related to both $v_{1}$ and $v_{2}$. To make a better illustration, we draw the stability domain diagram concerning $v_{1}$ and $v_{2}$.

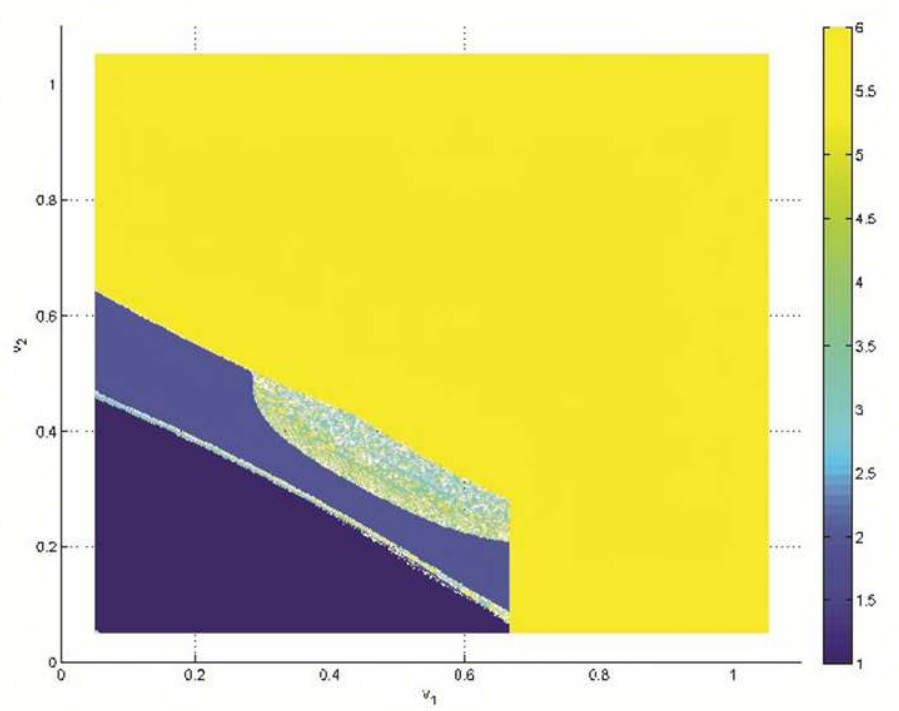

Fig. 7. The stable region of $v_{1}$ and $v_{2}$

In Fig.7, different color represents a different stability state. The Dark blue represents the model in a stable state, the light blue represents the model in the bifurcation phase, and the color of scattering represents the model in a chaotic state. According to this figure, the stability of the model decreases with the increase of 

reveal the trend of the profits of the manufacturers and the retailer. market stability.
428 \\ 429} adjustment speed $v_{1}$ and $v_{2}$, In other words, the swifter response indicates weaker

Next, we will further analyze the impact of the instability on the profits of manufacturers and retailers. The three-dimensional figures from Fig. 8 to Fig. 10

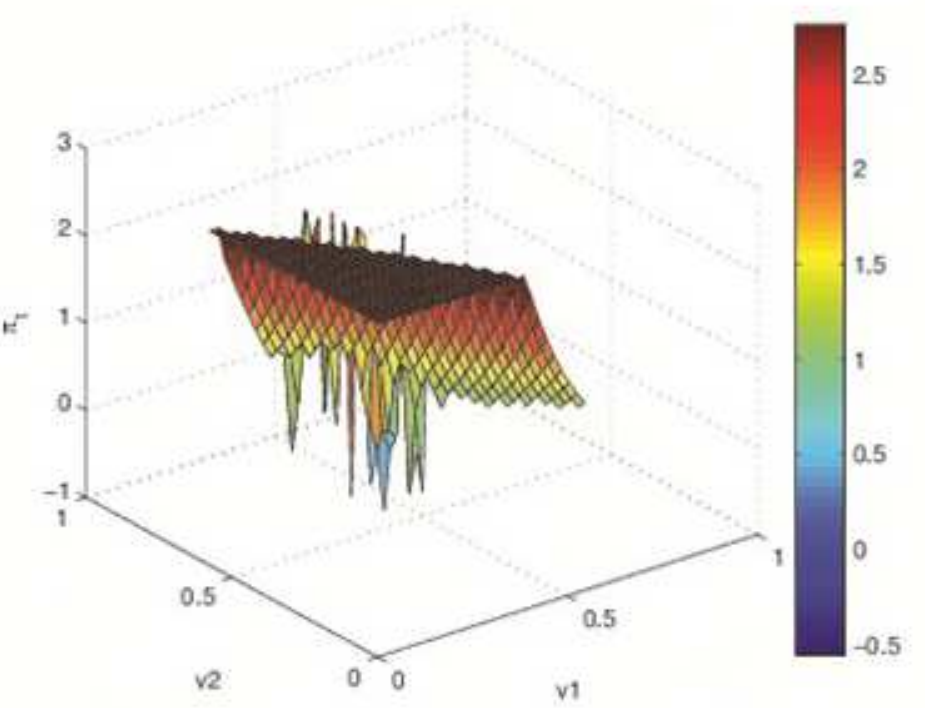

Fig. 8. The profit of the manufacturer 1 for $v_{1}$ and $v_{2}$

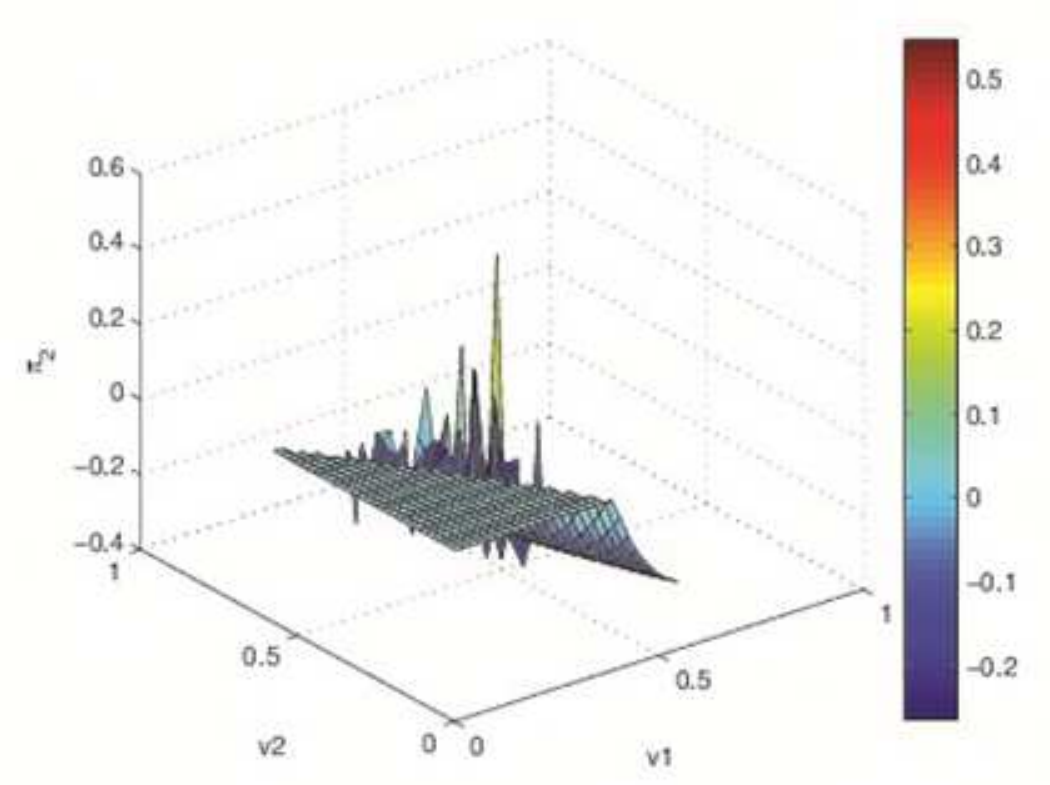

430

Fig. 9. The profit of the manufacturer 2 with respect to $v_{1}$ and $v_{2}$ 


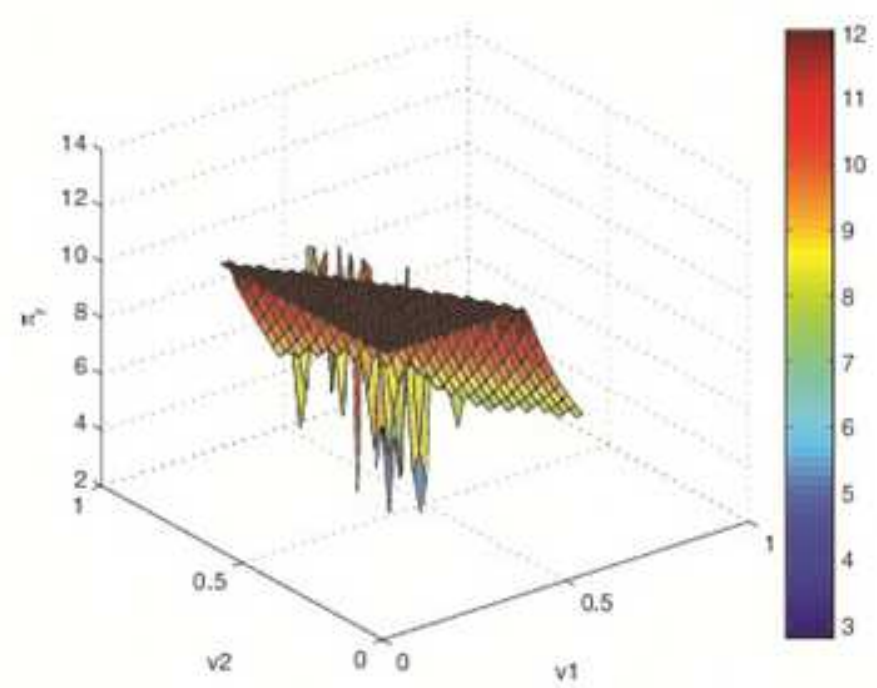

432

Fig. 10. The profit of the retailer with respect to $v_{1}$ and $v_{2}$

As expected, with the increase of the decision adjustment speed $v_{1}$ and $v_{2}$, the decision variables go unstable, resulting in the instability of the profits of manufacturers and retailers. And on average, both manufacturers and retailers have a profit loss in multiple cycles. Thus, the chaos is unfavorable for the entire market, which seriously affects the normal operation of the parties in the game.

\subsection{Impact from Parameters}

In addition to analyzing the speed of adjustment $v_{1}$ and $v_{2}$, how to impact the market of manufacturers and retailers. We also analyze the impact of several key parameters in the game on the evolution process from the perspective of profit, which is the concern of all parties.

\subsubsection{Cost reduction of manufacturer 1}

According to the above results, the stability of the system is related to the manufacturer's adjustment speed $v_{1}$ and $v_{2}$. With the increase of adjustment speed $v_{1}$ and $v_{2}$, the system goes from a stable state into an unpredictable instability. Here, we analyze the impact of cost reduction of manufacturer $1 d C_{1}$ and the profits of the three parties in the game under the stable state and the unstable state.

Based on the above analysis, we set $v_{1}=0.2$ and $v_{2}=0.2$ for the stable state while $v_{1}=0.3$ and $v_{2}=0.5$ for the unstable state. 


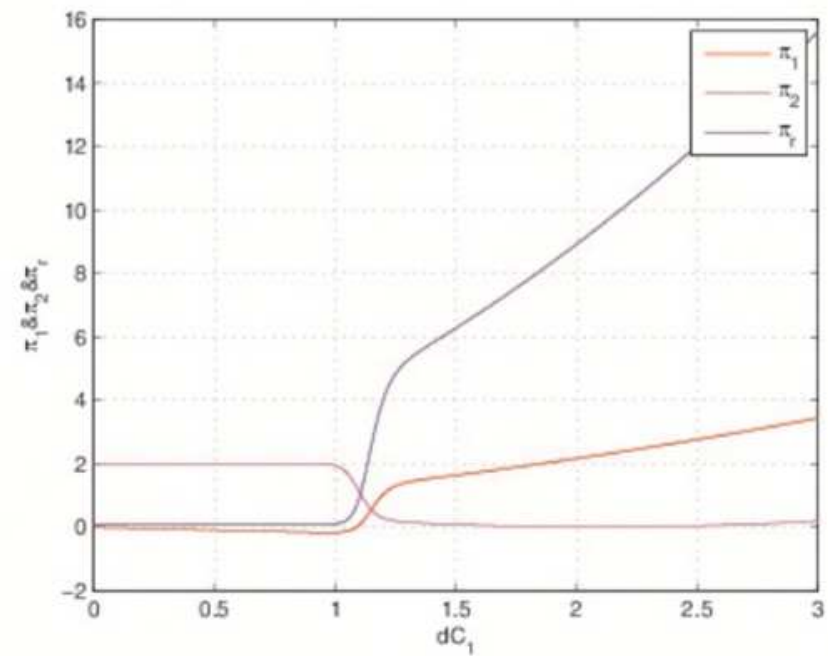

452

453

Fig. 11. Profit with respect to $d C_{1}$ when $v_{1}=0.2, v_{2}=0.2$

As shown in Fig.11, with the increase in cost reduction of manufacturer 1, the profit of manufacturer 1 and the retailer have a similar trend in the stable state. The change is indistinctive at the beginning and then goes significant. The profit trend of manufacturer 2 stays at first, then different from those of manufacturer 1 and the retailer, which decreases with a cost reduction of manufacturer 1 increasing. The profit with respect to the diagram in the unstable state can be seen in Fig.12

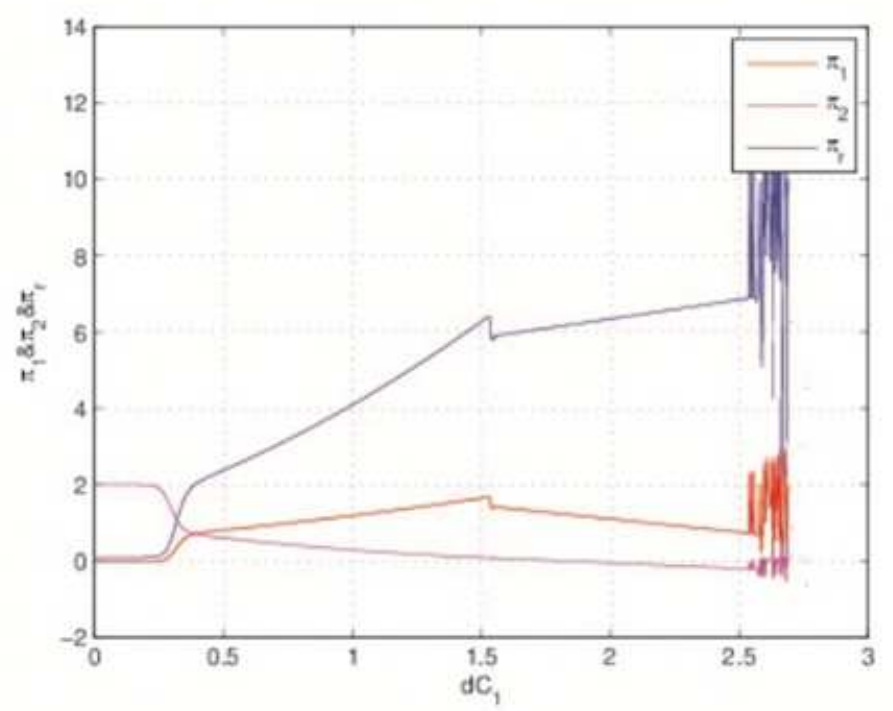

Fig. 12. Profit with respect to $d C_{1}$ when $v_{1}=0.3, v_{2}=0.5$

However, in the unstable state, the profit of manufacturer 1 and that of the retailer have a similar trend. They both have little change with the cost reduction $d C_{1}$ then go up and fall off a cliff finally. After that, the profit of manufacturer 1 keeps increasing and becomes fluctuant; meanwhile, the profit of the retailer keeps 
decreasing and becomes fluctuant. The explanation is that in the recycling stage, the retailer is responsible for recycling used products and sells them back to manufacturer 1, and a cooperative relationship forms between manufacturer 1 and the retailer. The similar trend of the profit of manufacturer 1 and that of the retailer is shown in Fig. 12. Manufacturer 2 also collects used products from the market, so he competes with manufacturer 1 and the retailer. In Fig. 12, with the cost reduction $d C_{1}$ increasing, the profit of manufacturer 2 remains stable first and then goes decreasing which is different from the trend of manufacturer 1 and the retailer. In the end, the profit of manufacturer 2 also becomes fluctuant.

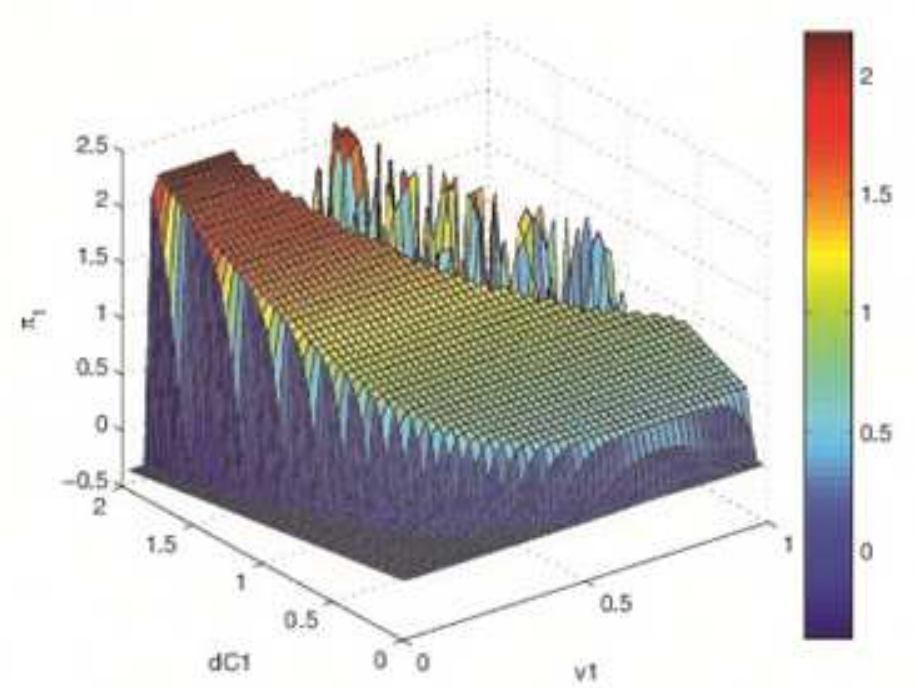

Fig. 13. Profit of manufacturer 1 with respect to $v_{1}$ and $d C_{1}$

For further analysis, we make a numerical simulation of the profit of manufacturer 1 with respect to the adjustment speed $v_{1}$ and cost reduction $d C_{1}$. Fig.13 shows the result. From Fig.13, we can get a similar conclusion that with the increase of cost reduction, the profit of manufacturer 1 is increasing. However, when the adjustment speed $v_{1}$ is far too high, the system will step into chaos and the manufacture will suffer profit losses.

\subsubsection{Cost reduction of manufacturer 2}

Similarly, we analyze the impact of cost reduction of manufacturer $2 d C_{2}$ on the profits of the three parties in the game in the stable state and the unstable state. And again we set $v_{1}=0.2$ and $v_{2}=0.2$ for the stable state while $v_{1}=0.3$ and $v_{2}=0.5$ for the unstable state.

The profit with respect to $d C_{2}$ when $v_{1}=0.2, v_{2}=0.2$ a diagram can be seen in Fig.14. 
490

491

492

493

494

495

496

497

498

499

500

501

502

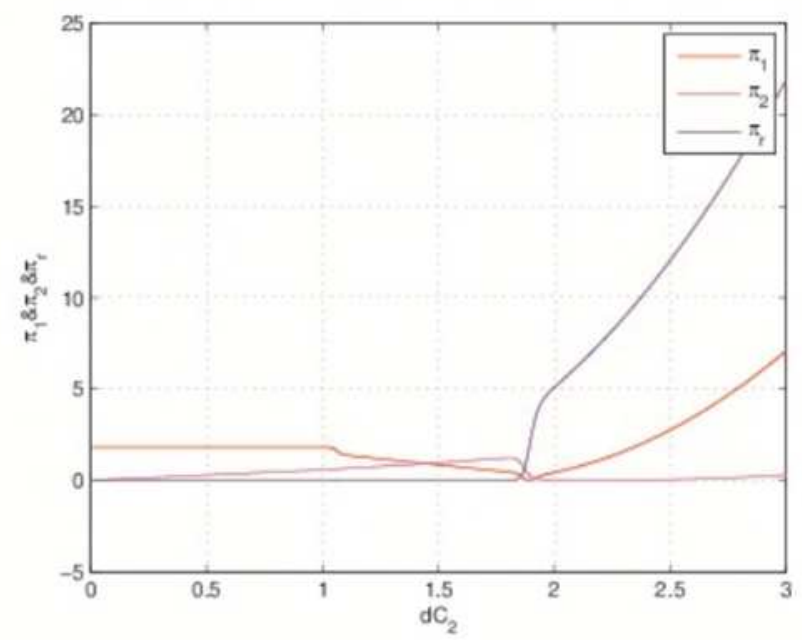

Fig. 14. Profit with respect to $d C_{2}$ when $v_{1}=0.2, v_{2}=0.2$

It's easy to find out that in the stable state, with the increase of its cost reduction $d C_{2}$, the profit of manufacturer 2 rises first and then decreases suddenly, after that, the profit of manufacturer 2 stays approximate to zero. While the profit of manufacturer 1 stays the same first and then drops, the profit of the retailer has no change at the same time. Then the profit of manufacturer 1 and that of the retailer increase simultaneously. There is a minimum value for the total profit of the three parties in the game. In general, the profit of each party is stable.

The profit with respect to $d C_{2}$ when $v_{1}=0.3, v_{2}=0.5$ the diagram can be seen in Fig. 15

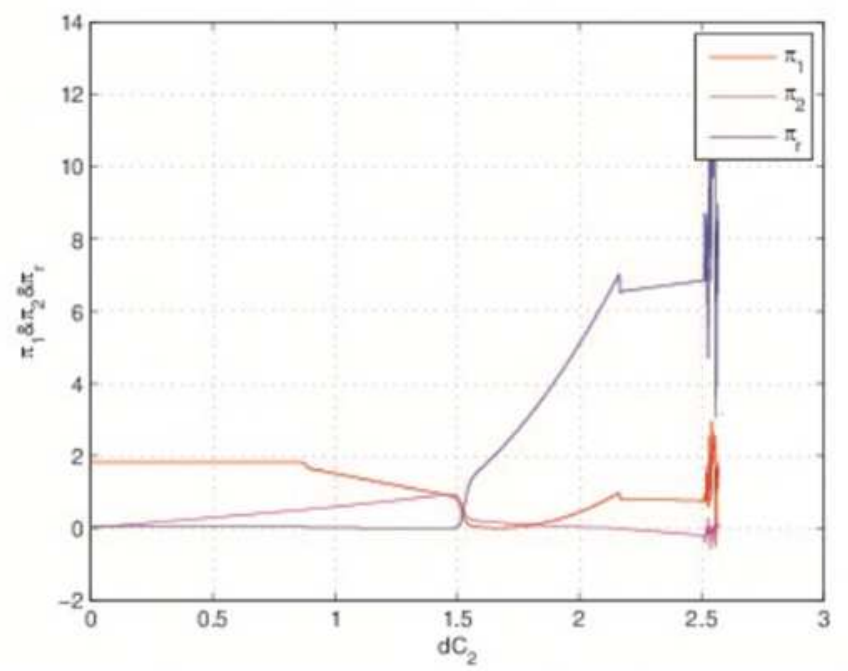

Fig. 15. Profit with respect to $d C_{2}$ when $v_{1}=0.3, v_{2}=0.5$

In the unstable state, it goes similarly to Fig.14 when the cost reduction $d C_{2}$ is 
small. Then the profit of manufacturer 1 and that of the retailer fall off a cliff. The profit of manufacturer 1 keeps decreasing; At the same time, the profit of manufacturer 2 decreases continuously. After that, with the increase in its cost reduction, the profit of the three parities fluctuate and becomes unstable, which is bad for all parties in the game.

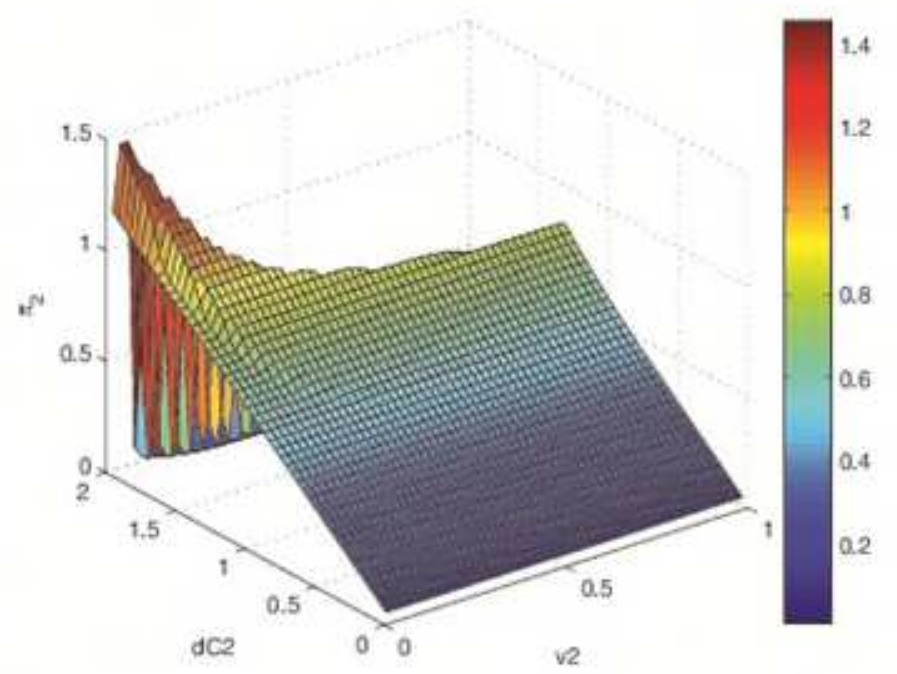

Fig. 16. Profit of manufacturer 2 with respect to $v_{2}$ and $d C_{2}$

As before, we analyze the profit of manufacturer 2 with respect to adjustment speed $v_{2}$ and cost reduction $d C_{2}$ and Fig.16 presents the result. From Fig.16, we can get a similar conclusion that with the increase of cost reduction $d C_{2}$, the profit of the manufacturer reaches the maximum and then drops off sharply. However, when the adjustment speed $v_{2}$ is too high, the system will step into chaos and it will take a toll on the profit.

\subsubsection{The price coefficient of the retailer}

Next, we move on to the price coefficient of the retailer $\lambda_{3}$ and explore its impact on the profit of the parties in the game. And we also set $v_{1}=0.2$ and $v_{2}=0.2$ for the stable state and $v_{1}=0.3 \quad v_{2}=0.5$ for the unstable state. 

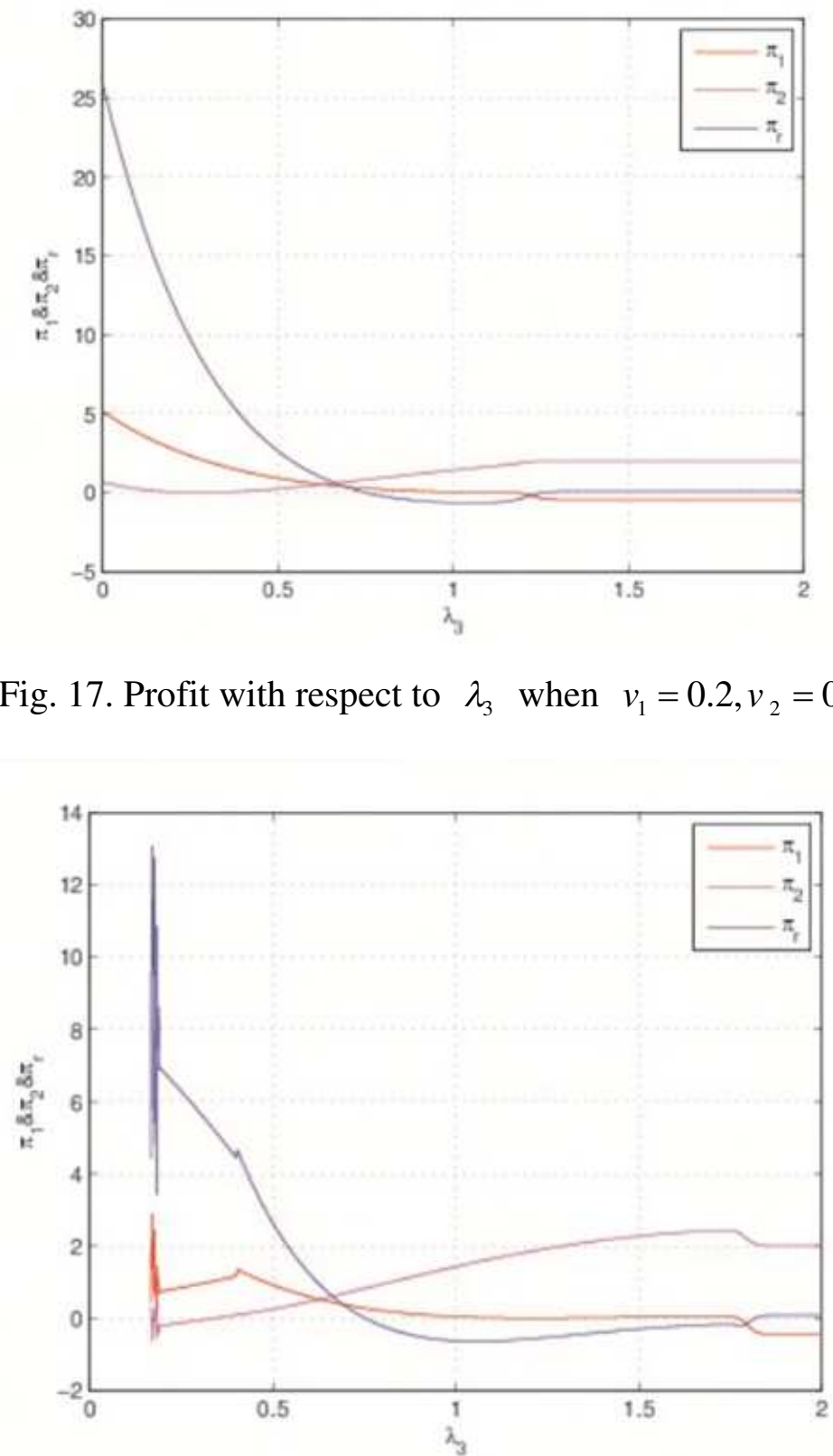

Fig. 18. Profit with respect to $\lambda_{3}$ when $v_{1}=0.3, v_{2}=0.5$

From the comparison of Fig.17 and Fig.18, it can be concluded that as for manufacturer 1 and the retailer, the smaller price coefficient of the retailer can bring higher profits, but also aggravates the chaotic condition in which the stability of the whole system will decrease. Thus, there is a contradiction between the profitability and the stability of the whole system. With the increasing price coefficient of the retailer, the profit of manufacturer 2 also increases in general, which is different from the trend of manufacturer1 and the retailer. 

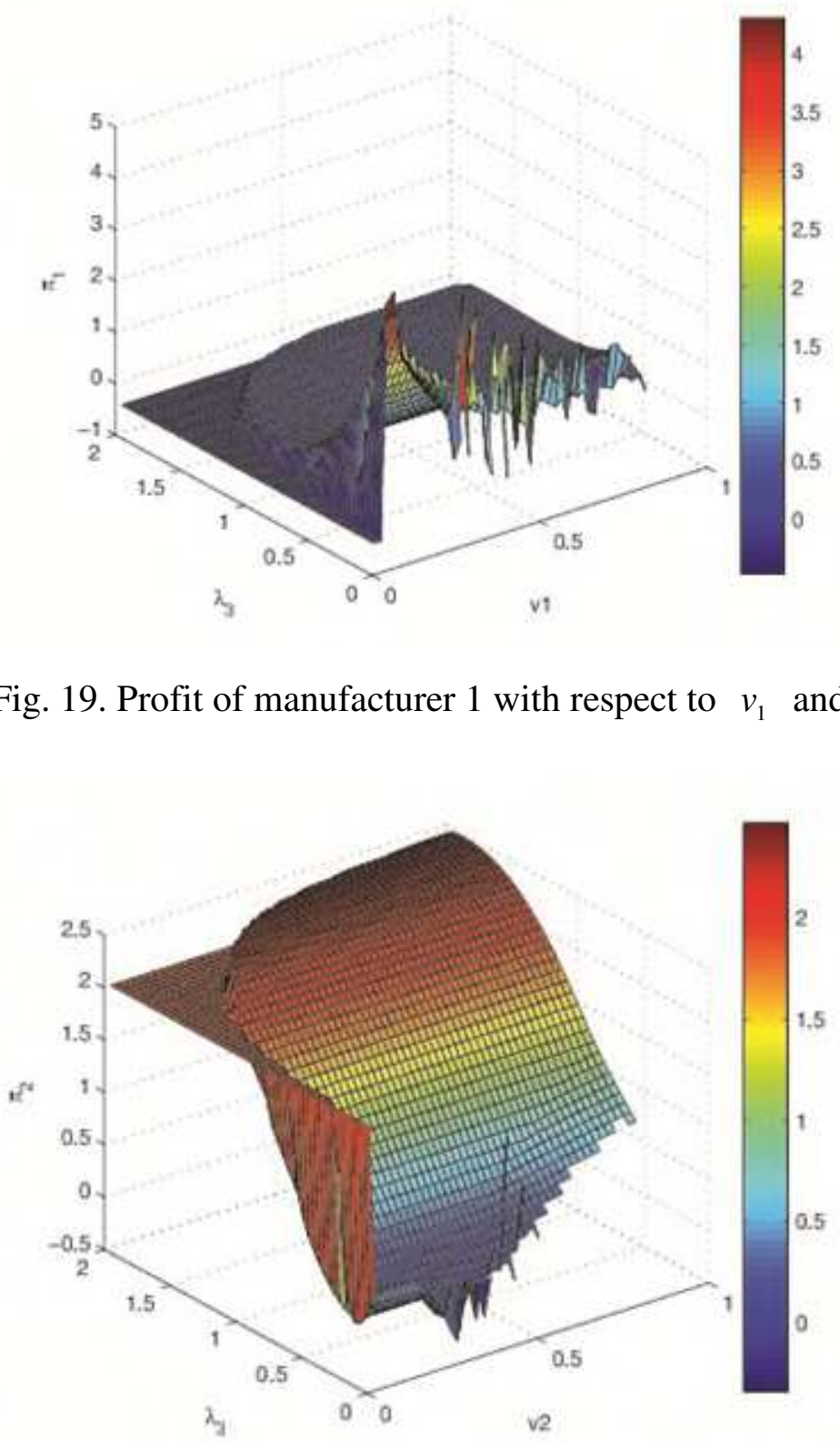

Fig. 20. Profit of manufacturer 1 with respect to $v_{2}$ and $\lambda_{3}$

From the above three-dimensional Fig.19 and Fig.20 we can also see that with the increase of the price coefficient of the retailer, the profit trend of manufacturer 1 and that of manufacturer 2 are opposite. As for manufacturer 1, the profit goes decreasing with the price coefficient of the retailer increasing; as for manufacturer 2 , the profit goes increasing with the price coefficient of the retailer increasing.

As we stated, when the state of the system becomes chaotic, that is, the market is in a chaotic state, the profit of the system will decrease and the decision-making process of supply chain's members will become more complicated than before, which is harmful to economic development. Therefore, we need to control the chaotic state to benefit the whole system. In this section, we control chaos from two aspects: 
adjusting the related parameters and the decision method.

(1) Parameter control method

As for manufacturer 1 and manufacturer 2, according to the above discussion and conclusion, $d C_{1}$ and $d C_{2}$ are two important parameters that can be improved. Then, we set parameters $v_{1}=0.4, v_{2}=0.4$ and study the change of the system stability with the change of different manufacturer cost variables. The results of numerical simulation are shown in Fig.21 and Fig.22.

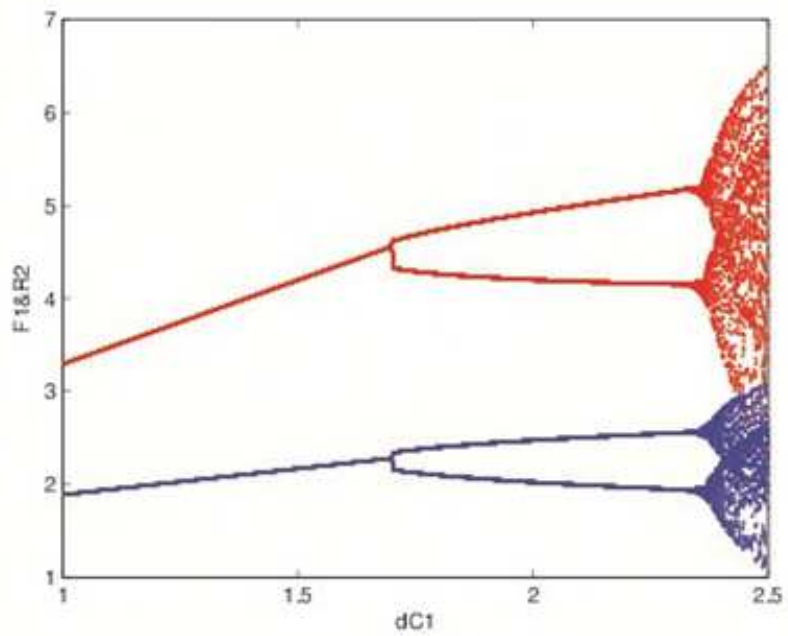

Fig.21. Bifurcation diagram with the change of $d C_{1}$ when $v_{1}=0.4, v_{2}=0.4$

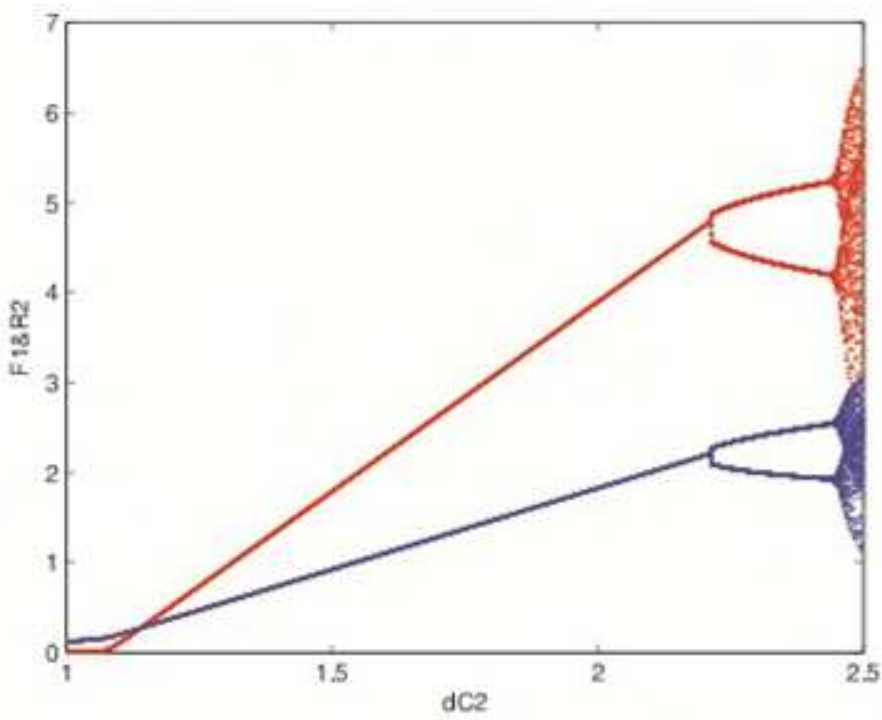

Fig.22. Bifurcation diagram with the change of $d C_{2}$ when $v_{1}=0.4, v_{2}=0.4$

In Fig.21 and Fig.22, we draw the trend of the change of decision variables with 
the change of $d C_{1}$ and $d C_{2}$. As can be seen in Fig.21 and Fig.22, with the increase of $d C_{1}$ and $d C_{2}$, the stability of the system declines, bifurcation, and chaos form. As for manufacturer 1 and manufacturer $2, d C_{1}$ and $d C_{2}$ represent profit margin between remanufacturing and manufacturing, and according to the conclusion we got, the profit of manufacturer 1 will increase with $d C_{1}$ increasing and the profit of manufacturer 2 will increase with $d C_{2}$ increasing. So profit and system stability need to be balanced, that is, manufacturers need to further optimize the manufacturing process of new products, and higher stability can be obtained through reducing $C_{1}$ and $C_{2}$.

As for the retailer, according to the above analysis, the retailer price coefficient $\lambda_{3}$, which represents the increase in retailer price, can be improved. The trend of the change of decision variables with the change $\lambda_{3}$ is shown in Fig.23.

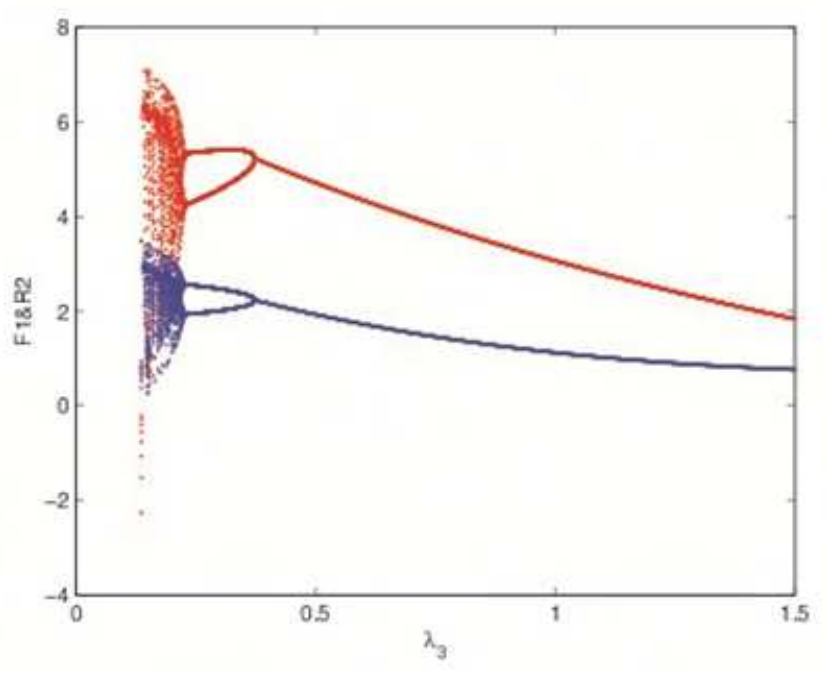

Fig.23. Bifurcation diagram with the change of $\lambda_{3}$ when $v_{1}=0.4, v_{2}=0.4$

In Fig.23, we can see that with the decrease of $\lambda_{3}$, the stability of the system declines, bifurcation and chaos form, which means the higher $\lambda_{3}$ is, the higher retailer price is, and the stronger system's stability is. Therefore, retailers can enhance their earnings stability by increasing the price of corresponding products.

(2) Decision-making method

Based on the characteristics of the whole decision-making process, we adopt an adaptive method to control the chaotic state. That is, when making decisions next period, we take not only decisions in this period into consideration, but also earlier decisions. Thus, the system can be summarized as follows. 


$$
\left\{\begin{array}{l}
F_{1}(t+1)=F_{1}(t)+v_{1} F_{1}(t) \frac{\partial \Pi_{1}^{\prime}}{\partial F_{1}}+v^{\prime}\left(F_{1}(t)-F_{1}(t-1)\right) \\
R_{2}(t+1)=R_{2}(t)+v_{2} R_{2}(t) \frac{\partial \Pi_{p}}{\partial R_{2}}+v^{\prime}\left(R_{2}(t)-R_{2}(t-1)\right)
\end{array}\right.
$$

We simplify equation (23) based on topological equivalence and then adopt $v_{1}=0.5, v_{2}=0.35$ and make Fig. 24 as follows to show the effect of the control parameter's control of chaos.

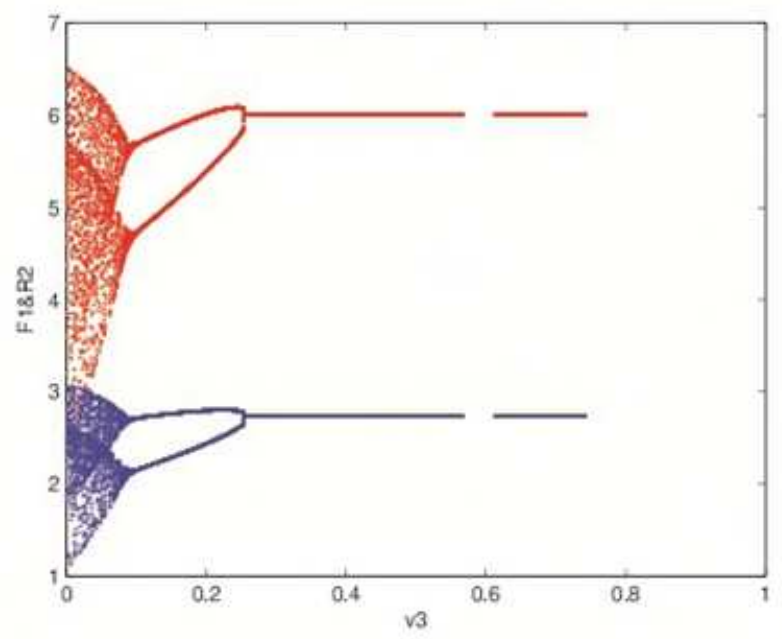

Fig. 24. Bifurcation diagram of decision variables with $v^{\prime}$ increasing

It can be seen from Fig. 24 that with the increasing control parameter $v^{\prime}$, the state of the system goes into period-doubling bifurcation from chaos and then becomes stable. When the system is in a stable state, players who make decisions in this game will obtain higher profits and make their own decisions more controllable.

In summary, we propose two methods of chaos control in the game process of two manufacturers and the retailer. In the parameter control method, we keep the enterprise decision-making adjustment speed and control system from the perspective of the actual production situation. As a result, we obtain final equilibrium. In the decision-making method, we maintain the original game situation and change the decision plan of the enterprises, which makes the response of the enterprise to the market delay. Manufacturers and the retailer can consider two methods based on the actual situation in the actual decision-making process.

\section{Conclusion and Policy Implications}

Studying the WEEE recycling activities has important ramifications for corporations, the whole supply chain system, and the market. In an electronics CLSC, more and more large retailers (eg: Mediaworld, Fnac, and Darty) offer 
recycling services to increase their attractiveness. Recycling services are extremely relevant for the key manufacturer, retailer, and customers in the supply chain. Especially, some kinds of electronic products are very difficult to transport and handle, which is beneficial to customers (De Giovanni, 2018).

In this paper, a closed-loop supply chain game model is constructed based on two recycling methods for product 1 . The influence of decision variables on the stability of the model is analyzed, and the stability control of the unstable system by two control methods is explored. The main findings of the paper get the following results.

(1) The results show that the stability of the model is related to the decision adjustment speed of the manufacturers. Excessive decision adjustment speed can easily lead to the unstable state of the system.

(2) At this time, the profits of the manufacturer and the retailer will become unstable, seriously affecting the normal operation of both sides of the game. If the adjustment speed of the manufacturers keeps in a rational value, players would achieve great benefits in the real market.

(3) The manufacturer's cost reduction is beneficial to itself as well as the retailer, but not to its competitor; the higher the retailer's price coefficient the higher the profit is, the more unstable the system will be.

(4) There are two kinds of methods are analyzed in this paper. They can be used to controlled chaotic. The chaotic control of the unstable system is carried out by adjusting the relevant parameters and adjusting the decision method. Both methods have a good control effect.

Besides, given the model studied in this paper, further research may be done from following two aspects: one is to consider the environmental benefits brought by waste recycling process; the other is to consider government intervention in this process, such as government subsidies, preferential tax on remanufactured products, etc. Our model can be extended to account for these aspects.

\section{Competing Interests}

The authors declare that they have no competing interests.

\section{Availability of data and materials}

Not applicable. 
642

643

644

645

646

647

648

649

650

651

652

653

654

655

656

657

658

659

660

661

662

663

664

665

666

667

668

669

670

671

672

673

674

675

676

677

678

\section{References}

Bal, Alperen, and Sule Itir Satoglu. "A goal programming model for sustainable reverse logistics operations planning and an application." Journal of cleaner production 201 (2018): 1081-1091.

Bing, X., Bloemhof-Ruwaard, J., Chaabane, A., \& van der Vorst, J. (2015). Global reverse supply chain redesign for household plastic waste under the emission trading scheme. Journal of cleaner production, 103, 28-39.

Bao, B., Ma, J. and Goh, M. Short- and long-term repeated game behaviours of two parallel supply chains based on government subsidy in the vehicle market. International Journal of Production Research, (2020): 1-24.

De Giovanni, Pietro. "A joint maximization incentive in closed-loop supply chains with competing retailers: The case of spent-battery recycling." European Journal of Operational Research 268.1 (2018): 128-147.

De Giovanni, Pietro, and Georges Zaccour. "A two-period game of a closed-loop supply chain." European Journal of Operational Research 232.1 (2014): 22-40.

$\mathrm{Du}$, Jian-guo, et al. "Dynamics analysis and chaos control of a duopoly game with heterogeneous players and output limiter." Economic Modelling 33 (2013): 507-516.

Elsadany, A. A. "Dynamics of a delayed duopoly game with bounded rationality." Mathematical and Computer Modelling 52.9-10 (2010): 1479-1489.

Guo, Qinxin, et al. "Profit or environment? A system dynamic model analysis of waste electrical and electronic equipment management system in China." Journal of cleaner production 194 (2018): 34-42.

$\mathrm{Gu}$, Yifan, et al. "To realize better extended producer responsibility: Redesign of WEEE fund mode in China." Journal of Cleaner Production 164 (2017): 347-356.

Gao, Juhong, et al. "Pricing and effort decisions in a closed-loop supply chain under different channel power structures." Journal of Cleaner Production 112 (2016): 2043-2057.

Guo, Yuehong, and Junhai Ma. "Research on game model and complexity of retailer collecting and selling in closed-loop supply chain." Applied Mathematical Modelling 37.7 (2013): 5047-5058.

Hong, Xianpei, et al. "Quantity and collection decisions in a closed-loop supply chain with technology licensing." European Journal of Operational Research 256.3 (2017): 820-829.

Huang, Min, et al. "Analysis for strategy of closed-loop supply chain with dual recycling channel." International Journal of Production Economics 144.2 (2013): 510-520.

$\mathrm{Lu}$, Bin, et al. "Perspectives on reuse of WEEE in China: lessons from the 
EU." Resources, Conservation and Recycling 135 (2018): 83-92.

Savaskan, R. Canan, S. Bhattacharya, and L. N. V. Wassenhove. "Closed-loop supply chain models with product remanufacturing." Management science 50.2 (2004): 239-252.

Liu, Zhi, et al. "Trade-off between remanufacturing and recycling of WEEE and the environmental implication under the Chinese Fund Policy." Journal of cleaner production 167 (2017): 97-109.

Liu, Huihui, et al. "A dual channel, quality-based price competition model for the WEEE recycling market with government subsidy." Omega 59 (2016): 290-302.

Ma, J., Zhang, F. and Jiang, H.. Dynamic Pricing Game Under Different Channel Power Structures in a Closed-Loop Supply Chain. International Journal of Bifurcation and Chaos, 30.04 (2020): 2050052.

Ma, Wei-min, Zhang Zhao, and Hua Ke. "Dual-channel closed-loop supply chain with government consumption-subsidy." European Journal of Operational Research 226.2 (2013): 221-227.

Ma, Junhai, and Zhanbing Guo. "The parameter basin and complex of dynamic game with estimation and two-stage consideration." Applied Mathematics and Computation 248 (2014): 131-142.

Ma, Junhai, and Fang Wu. "The application and complexity analysis about a high-dimension discrete dynamical system based on heterogeneous triopoly game with multi-product." Nonlinear Dynamics 77.3 (2014): 781-792.

Ma, Junhai, and Hongwu Wang. "Complexity analysis of dynamic noncooperative game models for closed-loop supply chain with product recovery." Applied Mathematical Modelling 38.23 (2014): 5562-5572.

Ma, J., Hou, Y. et al. A time-based pricing game in a competitive vehicle market regarding the intervention of carbon emission reduction. Energy Policy, 142 (2020), 111440.

Östlin, Johan, Erik Sundin, and Mats Björkman. "Importance of closed-loop supply chain relationships for product remanufacturing." International Journal of Production Economics 115.2 (2008): 336-348.

Polat, Olcay, Ozan Capraz, and Askiner Gungor. "Modelling of WEEE recycling operation planning under uncertainty." Journal of cleaner production 180 (2018): 769-779.

Qiang, Qiang, et al. "The closed-loop supply chain network with competition, distribution channel investment, and uncertainties." Omega 41.2 (2013): 186-194.

Savaskan, R. Canan, and Luk N. Van Wassenhove. "Reverse channel design: the case of competing retailers." Management science 52.1 (2006): 1-14.

Savaskan, R. Canan, S. Bhattacharya, and L. N. V. Wassenhove. "Closed-Loop Supply 
717 Chain Models with Product Remanufacturing." Management

718 Science 50.2(2004):239-252.

719 Tian, Y., Ma, J. et al. " Coordination and control of multi-channel supply chain driven

720 by consumers' channel preference and sales effort. " Chaos Solitons \& Fractals, 132

721 (2020):109576.

722 Wei, Jie, et al. "Pricing and collecting decisions in a closed-loop supply chain with

723 symmetric and asymmetric information." Computers \& Operations Research 54

724 (2015): 257-265.

725 Xu, Z., Elomri, A., Pokharel, S., Zhang, Q., Ming, X. G., \& Liu, W. (2017). Global

726 reverse supply chain design for solid waste recycling under uncertainties and carbon

727 emission constraint. Waste management, 64, 358-370.

728 Xie, L., Ma, J. and Goh, M. Supply chain coordination in the presence of uncertain

729 yield and demand. International Journal of Production Research, (2020), 1-17.

730 Xie, Lei, and Junhai Ma. "Study the complexity and control of the recycling-supply

731 chain of China's color TVs market based on the government

732 subsidy." Communications in Nonlinear Science and Numerical Simulation 38 (2016):

733 102-116.

734 Yin, Shuya, et al. "Durable products with multiple used goods markets: Product

735 upgrade and retail pricing implications." Marketing Science 29.3 (2010): 540-560.

736 Zhou, Wenhui, Yanfang Zheng, and Weixiang Huang. "Competitive advantage of

737 qualified WEEE recyclers through EPR legislation." European Journal of 738 Operational Research 257.2 (2017): 641-655.

739 Zlamparet, Gabriel Ionut, et al. "Remanufacturing strategies: A solution for WEEE 740 problem." Journal of cleaner production 149 (2017): 126-136. 
Figures

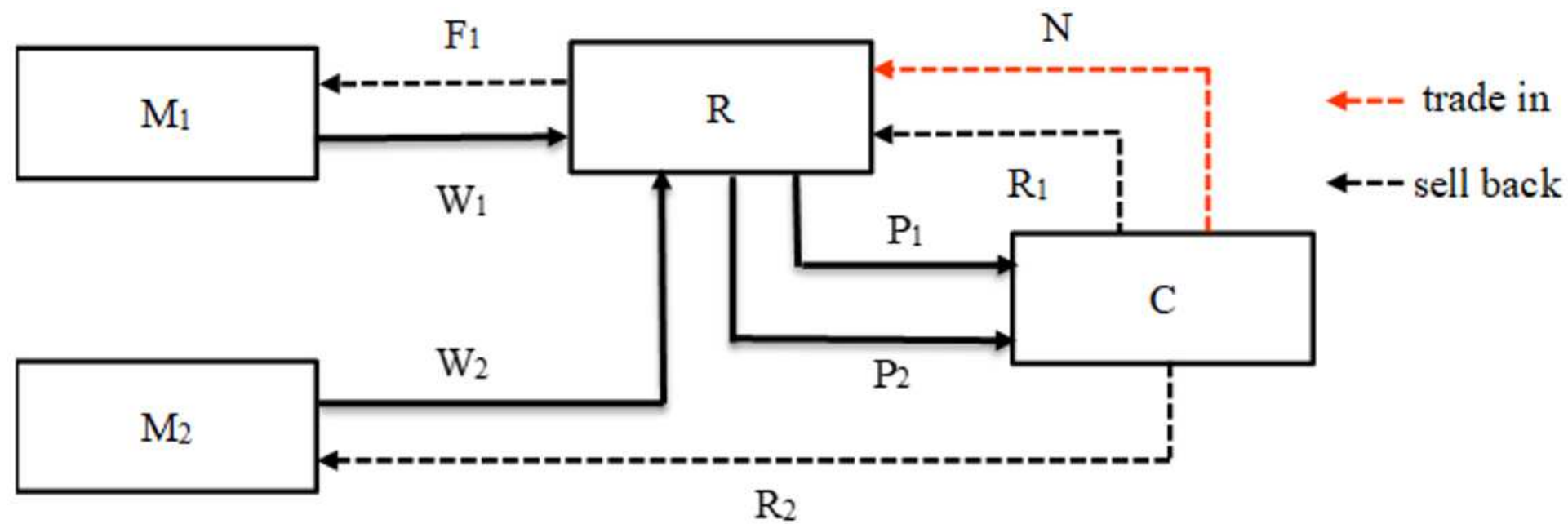

Figure 1

Recycling Supply Chain Model 


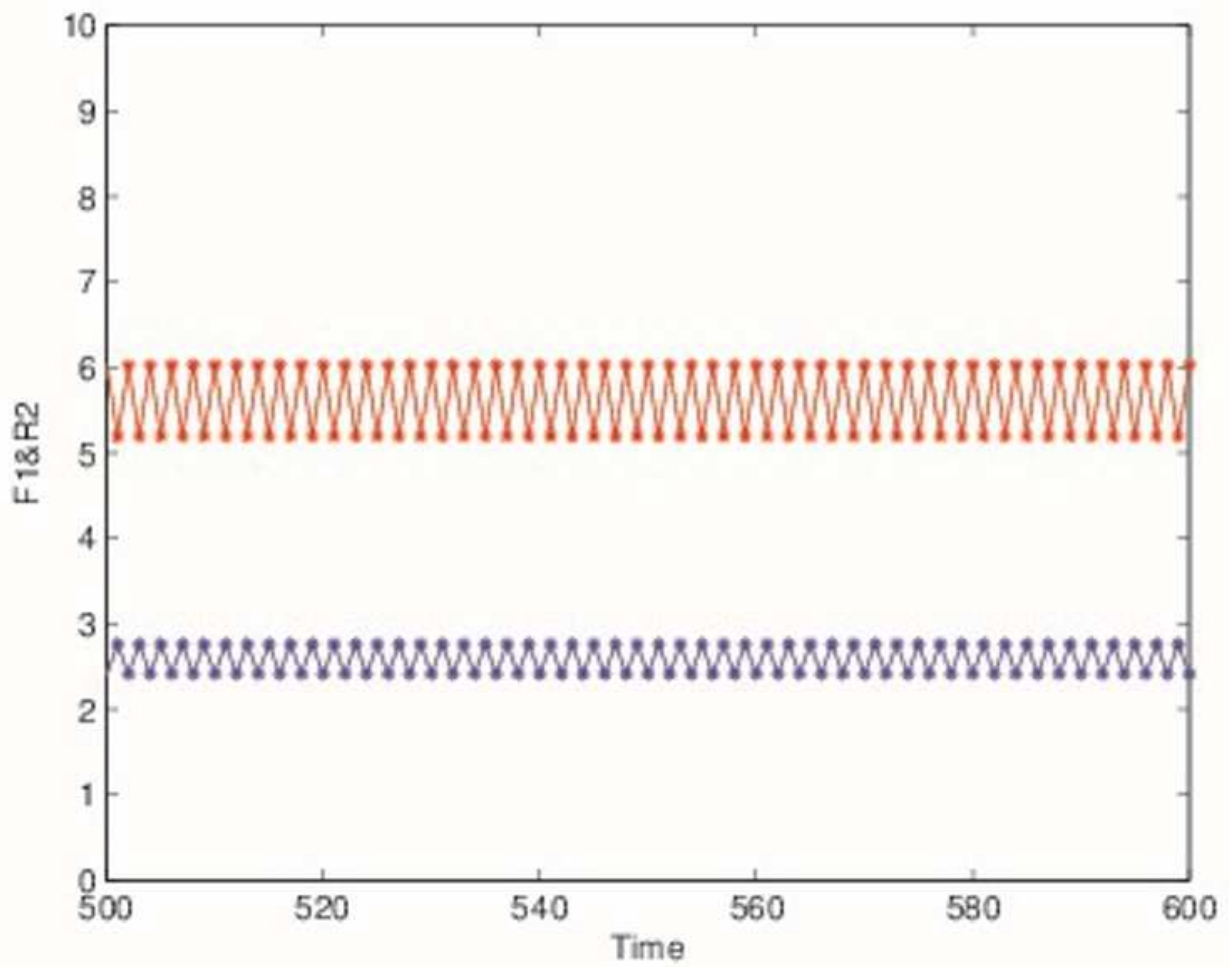

Figure 2

Time Sequence Diagram 


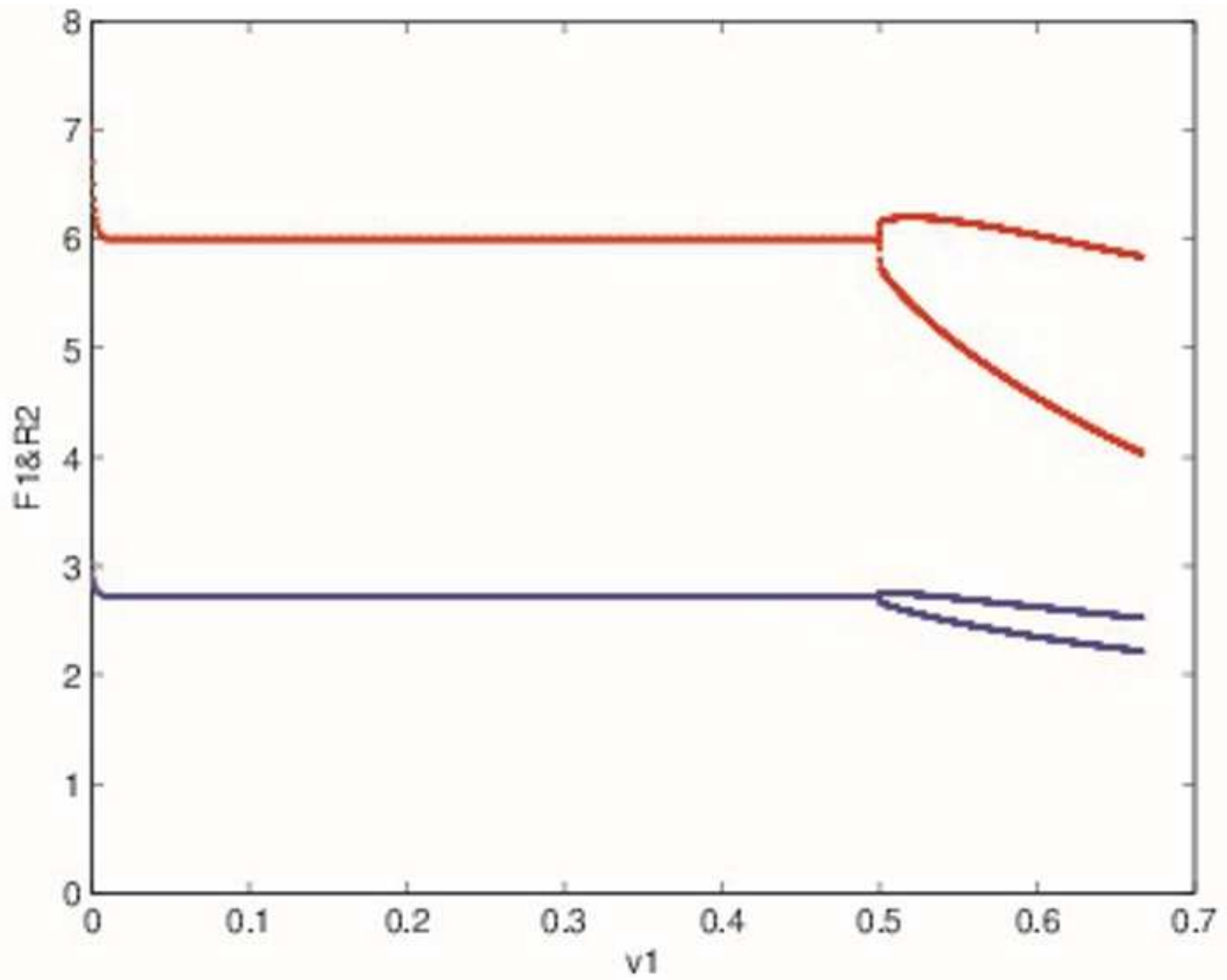

Figure 3

Bifurcation diagram when $\mathrm{v} 2=0.1$ 


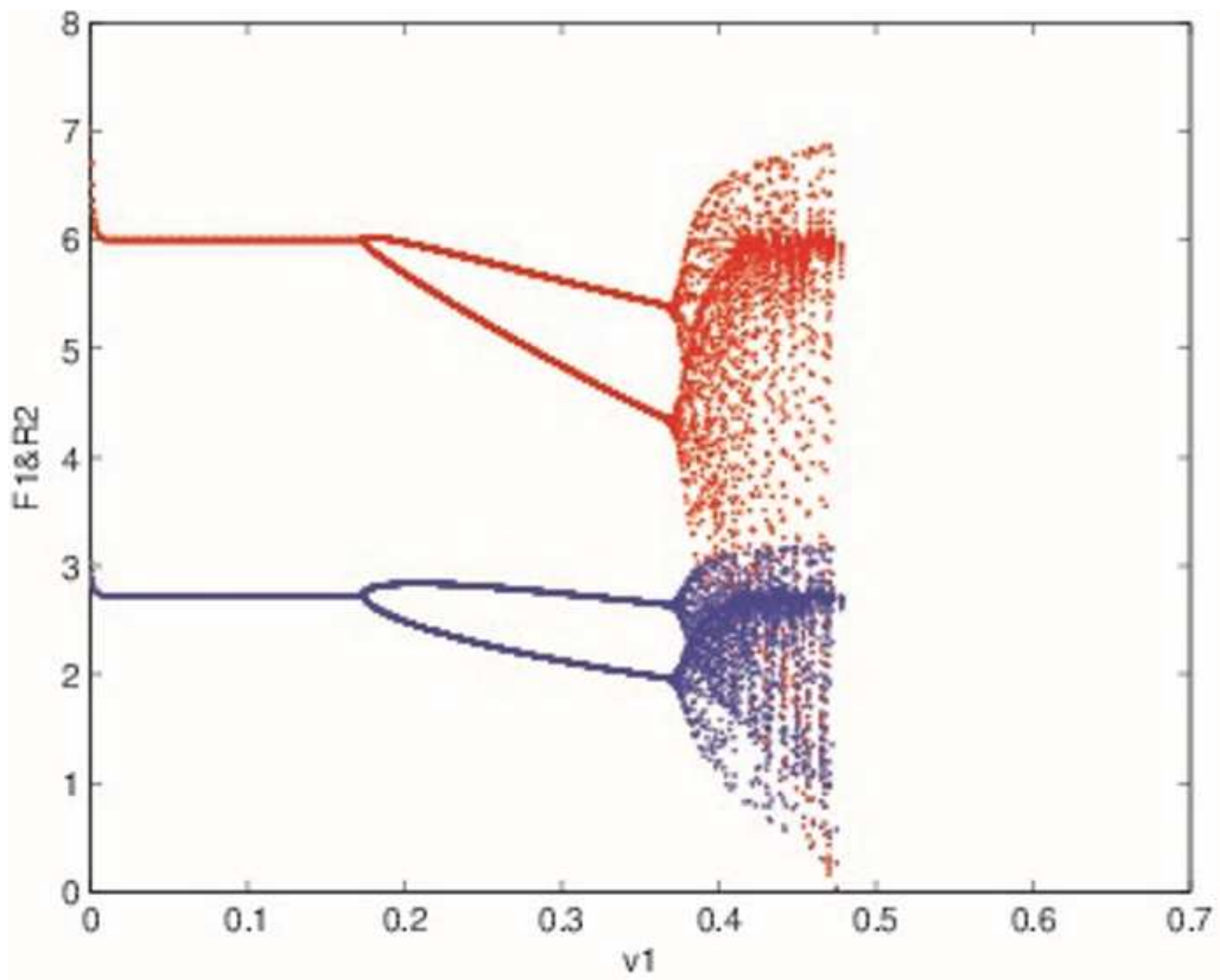

Figure 4

Bifurcation diagram when $\mathrm{v} 2=0.3$ 


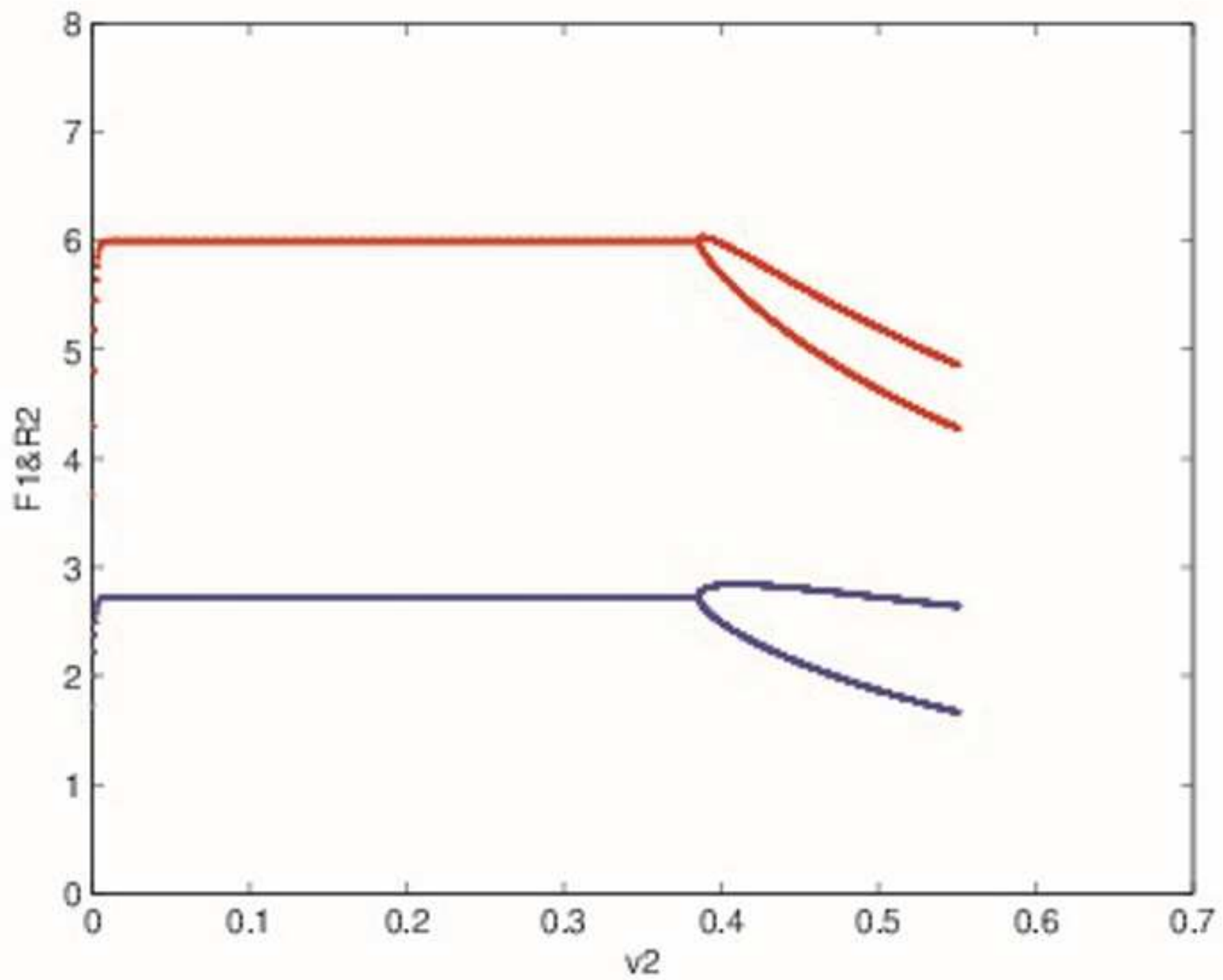

Figure 5

Bifurcation diagram when $\mathrm{v} 1=0.1$ 


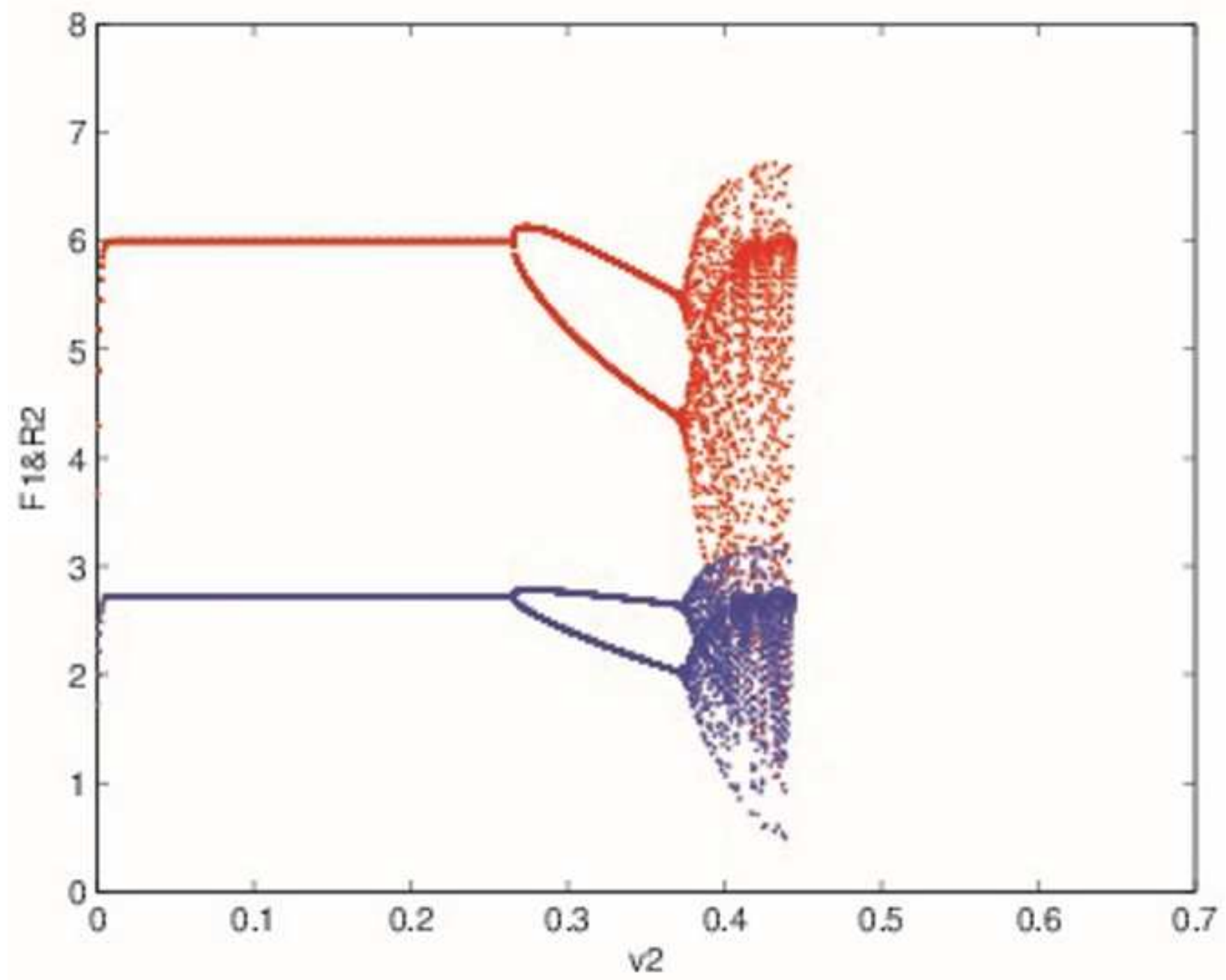

Figure 6

Bifurcation diagram when $\mathrm{v} 1=0.5$ 


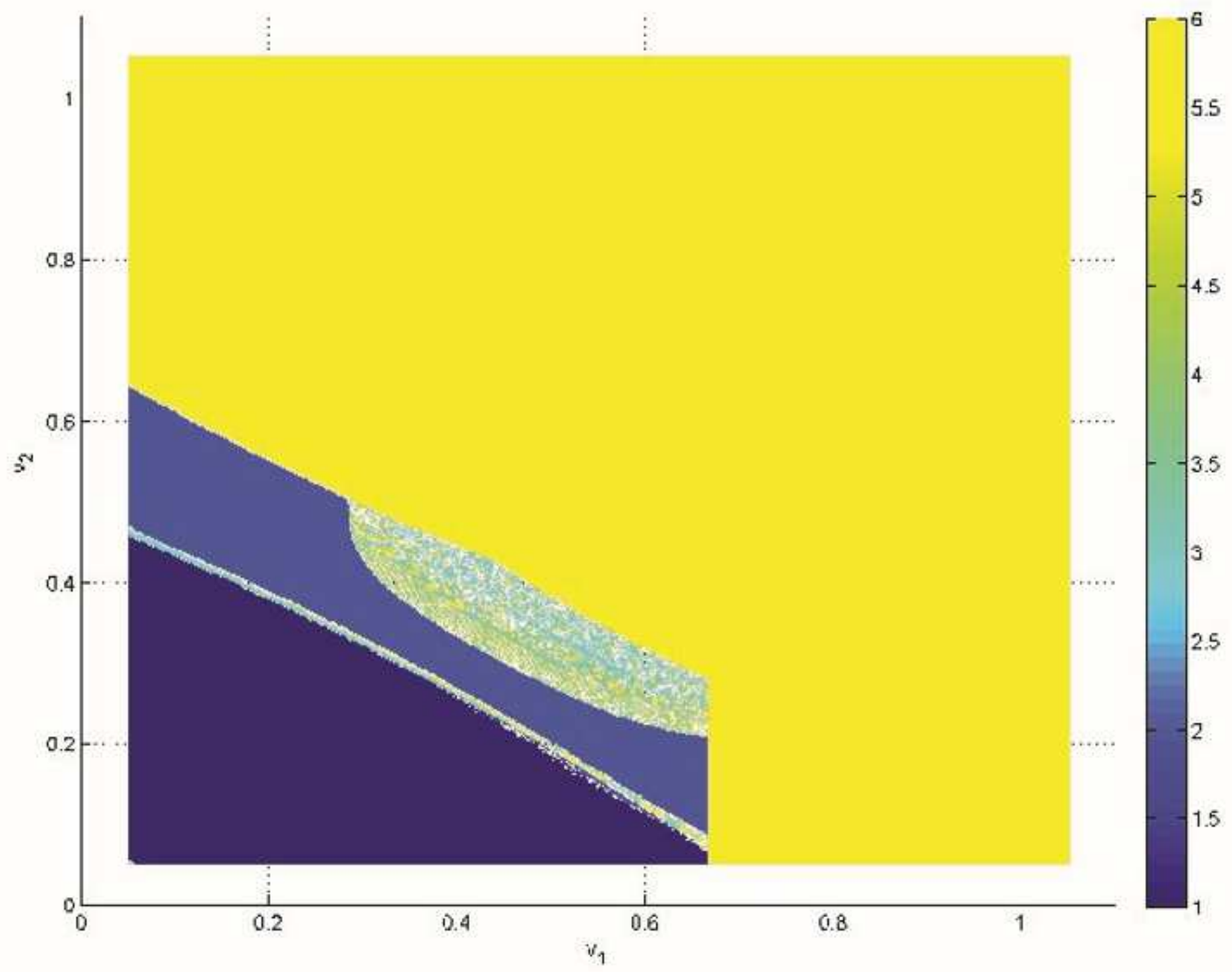

Figure 7

The stable region of $\mathrm{v} 1$ and $\mathrm{v} 2$ 


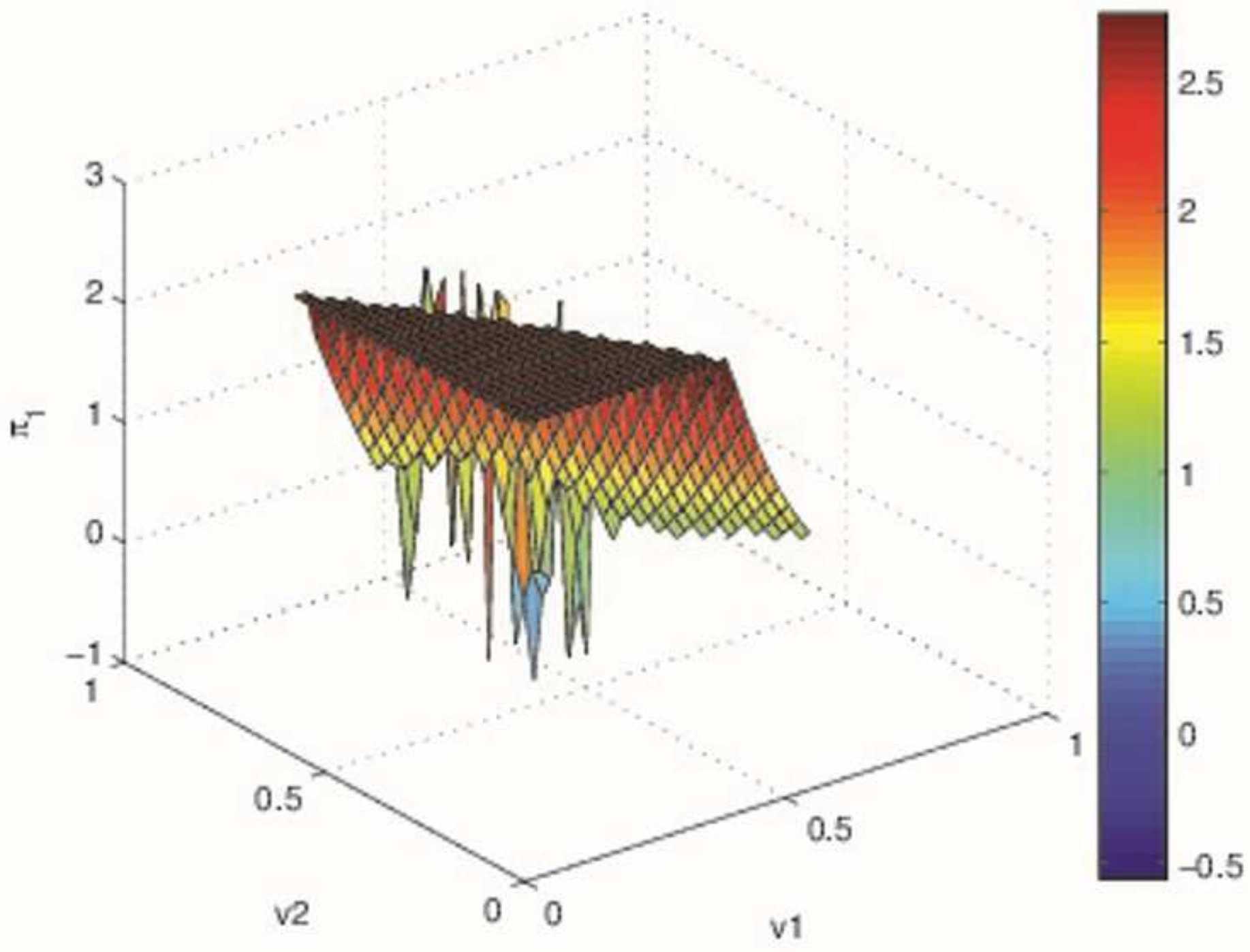

Figure 8

The profit of the manufacturer 1 for $\mathrm{v} 1$ and $\mathrm{v} 2$ 


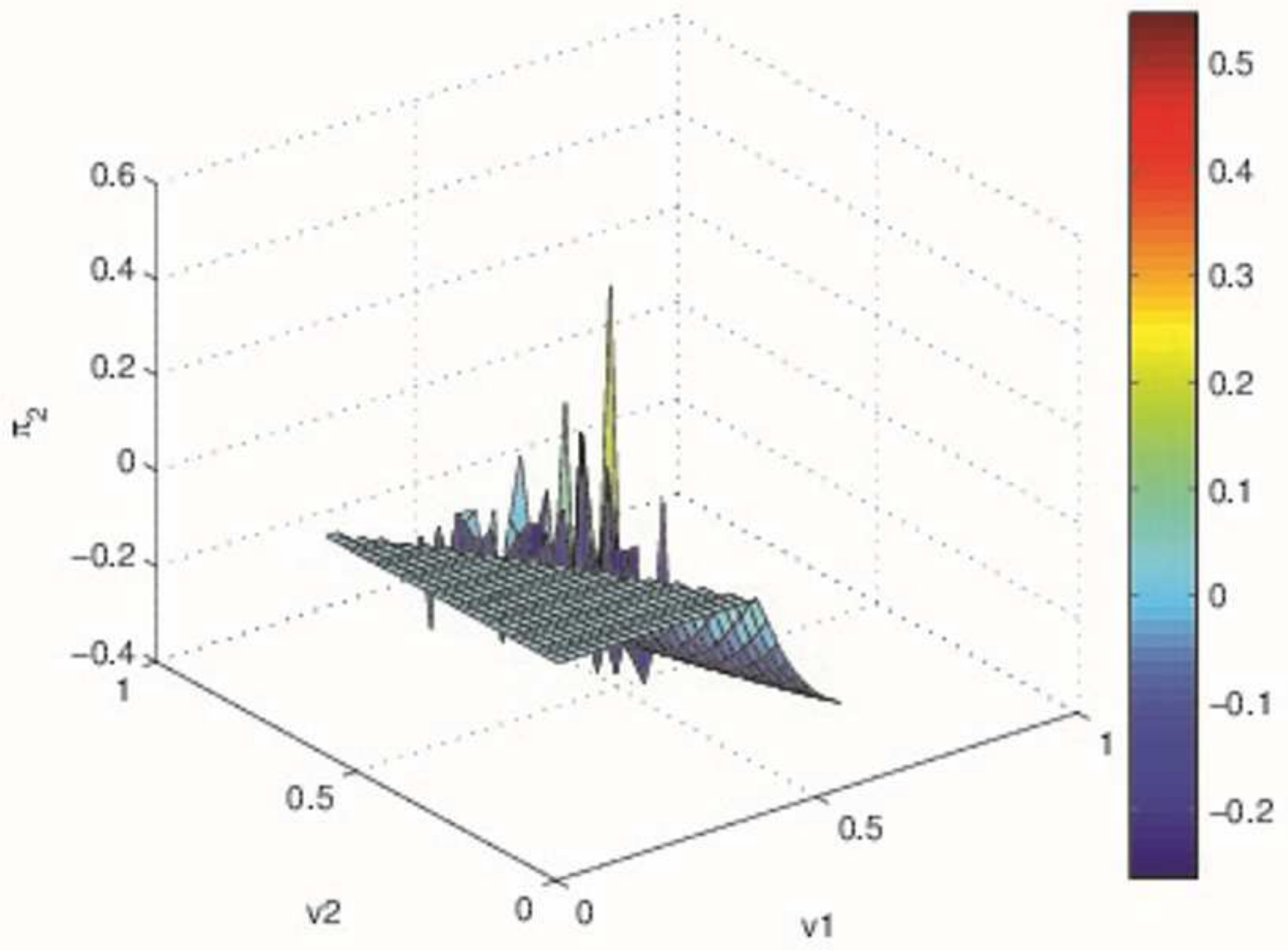

Figure 9

The profit of the manufacturer 2 with respect to $\mathrm{v} 1$ and $\mathrm{v} 2$ 


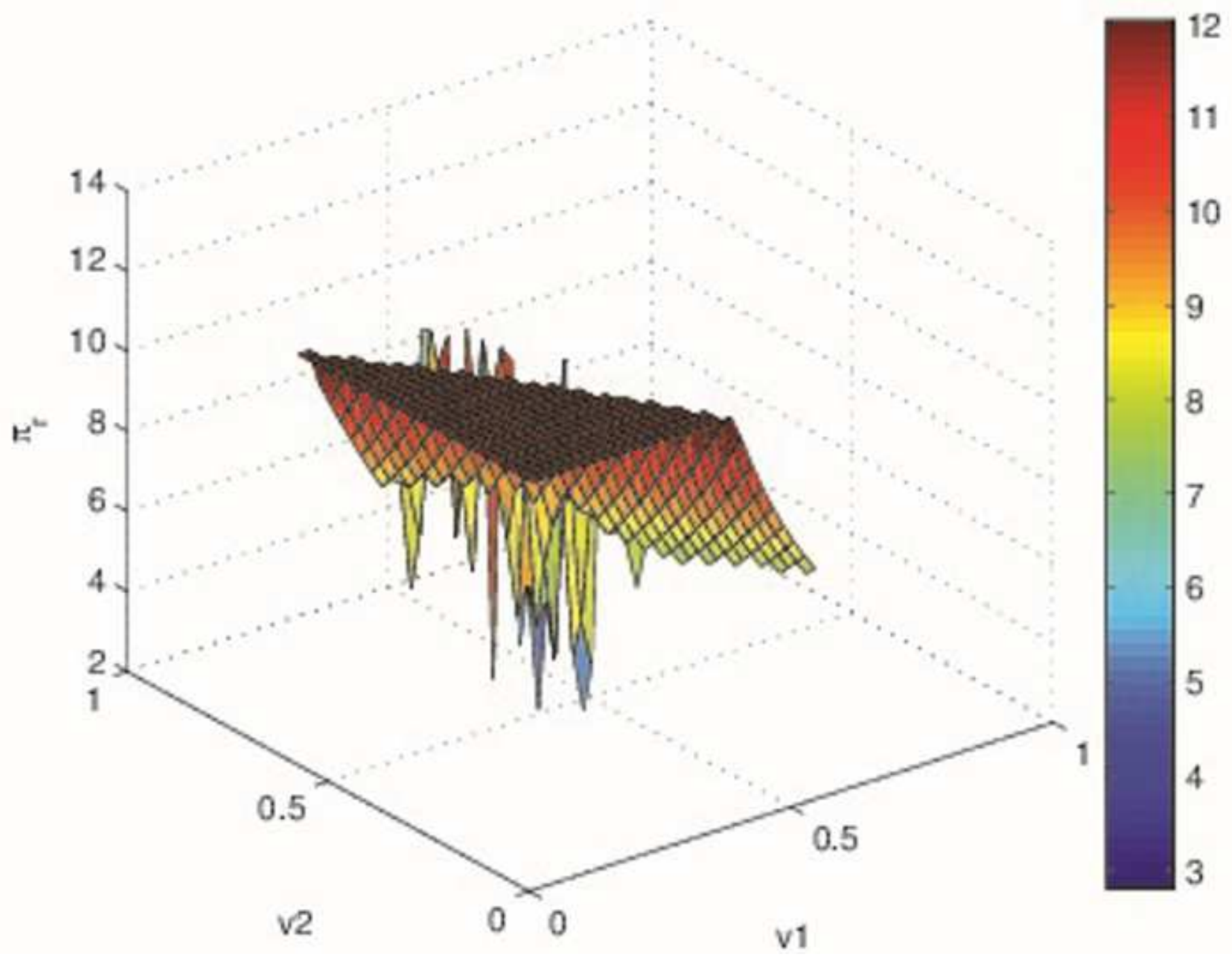

Figure 10

The profit of the retailer with respect to $\mathrm{v} 1$ and $\mathrm{v} 2$ 


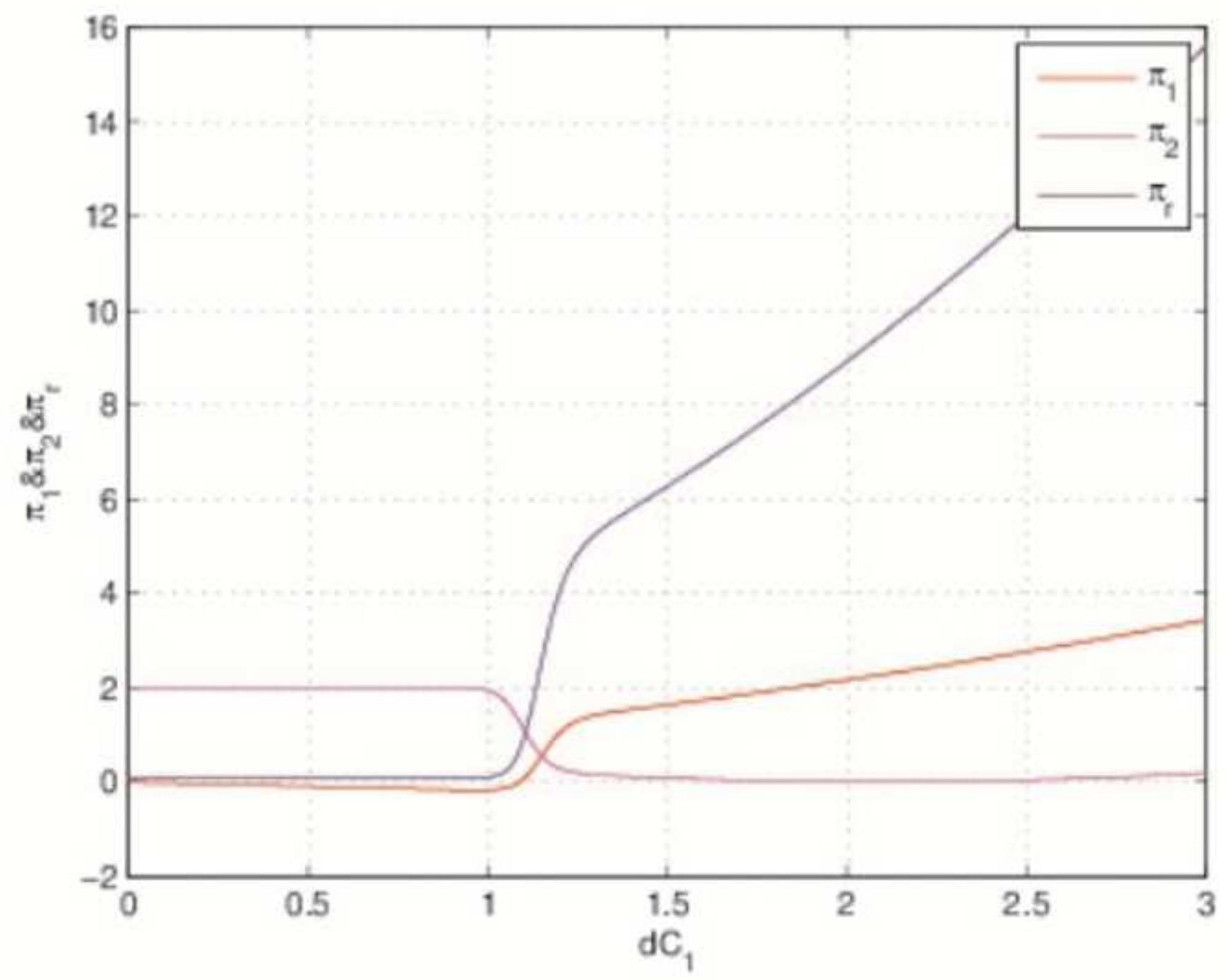

Figure 11

Profit with respect to $\mathrm{dC} 1$ when $\mathrm{v} 1=0.2, \mathrm{v} 2=0.2$ 


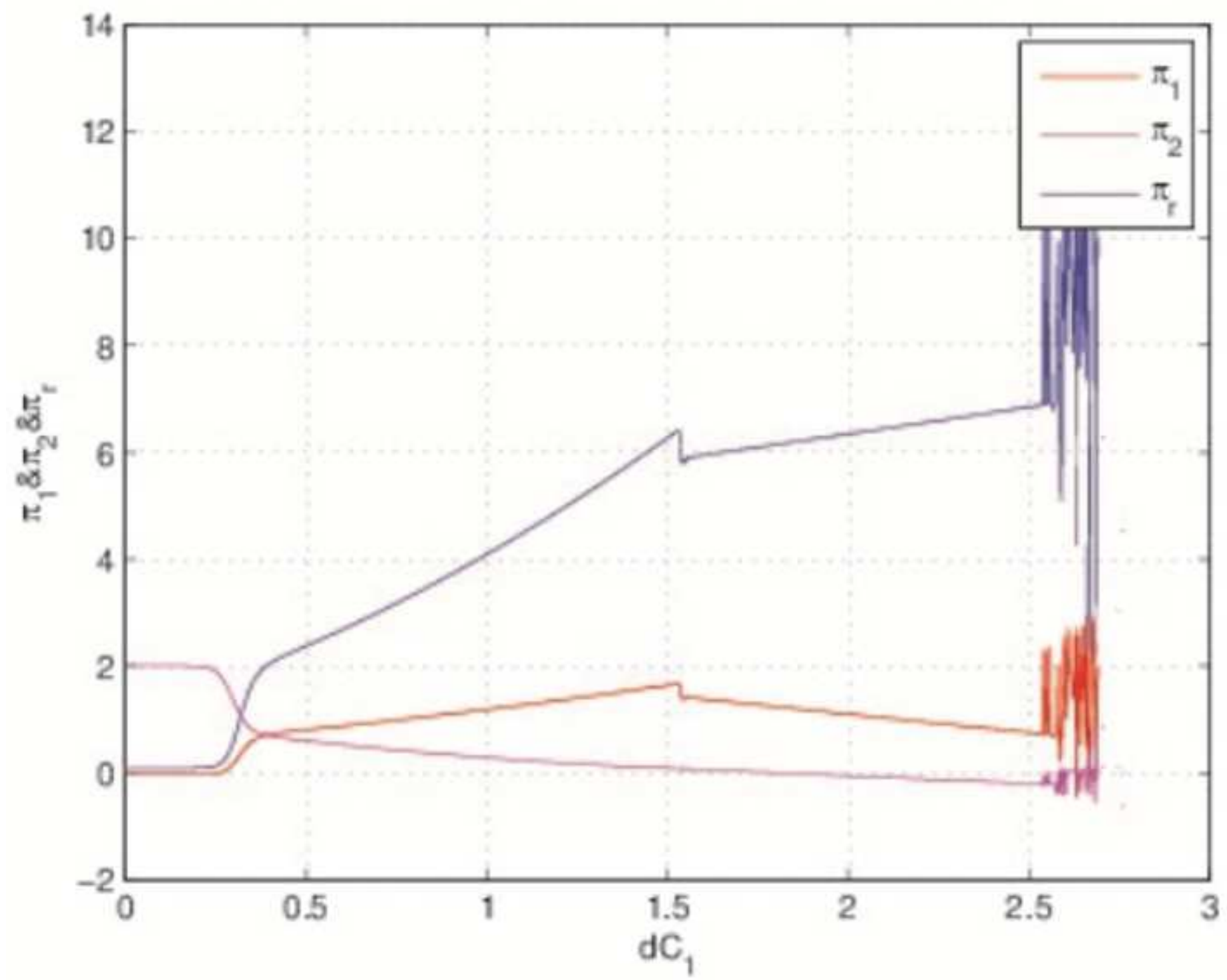

Figure 12

Profit with respect to $\mathrm{dC} 1$ when $\mathrm{v} 1=0.3, \mathrm{v} 2=0.5$ 


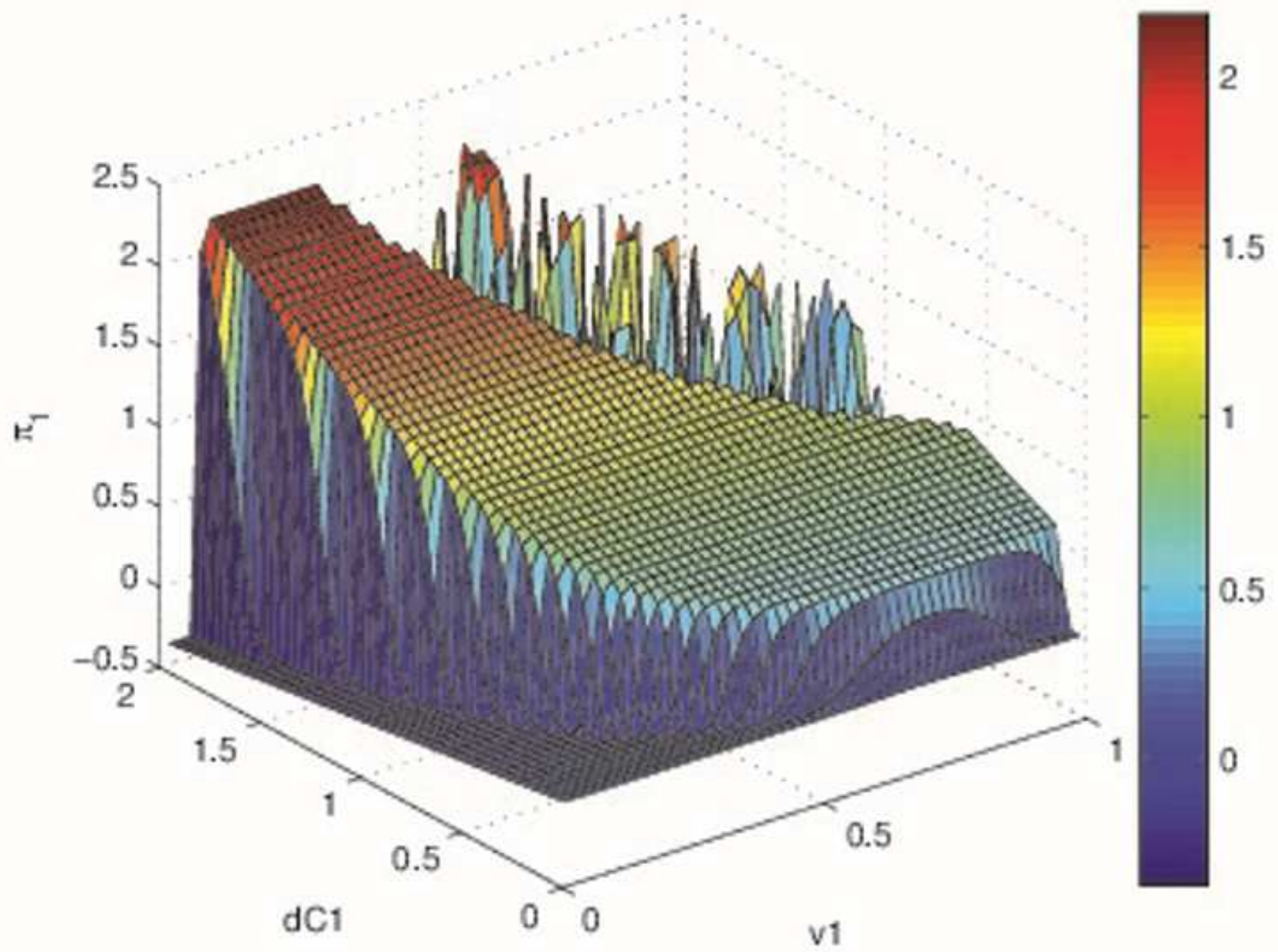

Figure 13

Profit of manufacturer 1 with respect to $\mathrm{v} 1$ and $\mathrm{dC} 1$ 


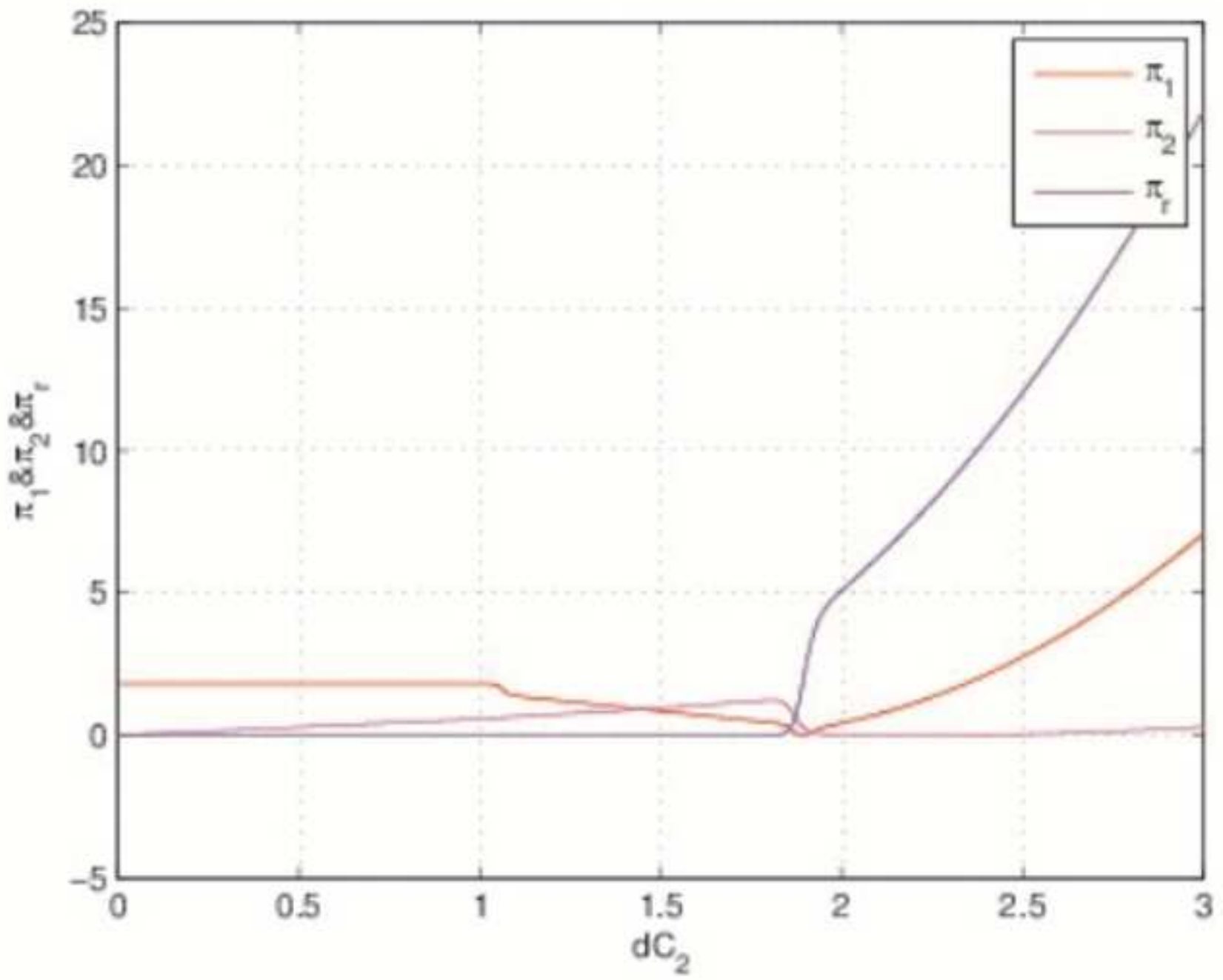

Figure 14

Profit with respect to $\mathrm{dC} 2$ when $\mathrm{v} 1=0.2, \mathrm{v} 2=0.2$ 


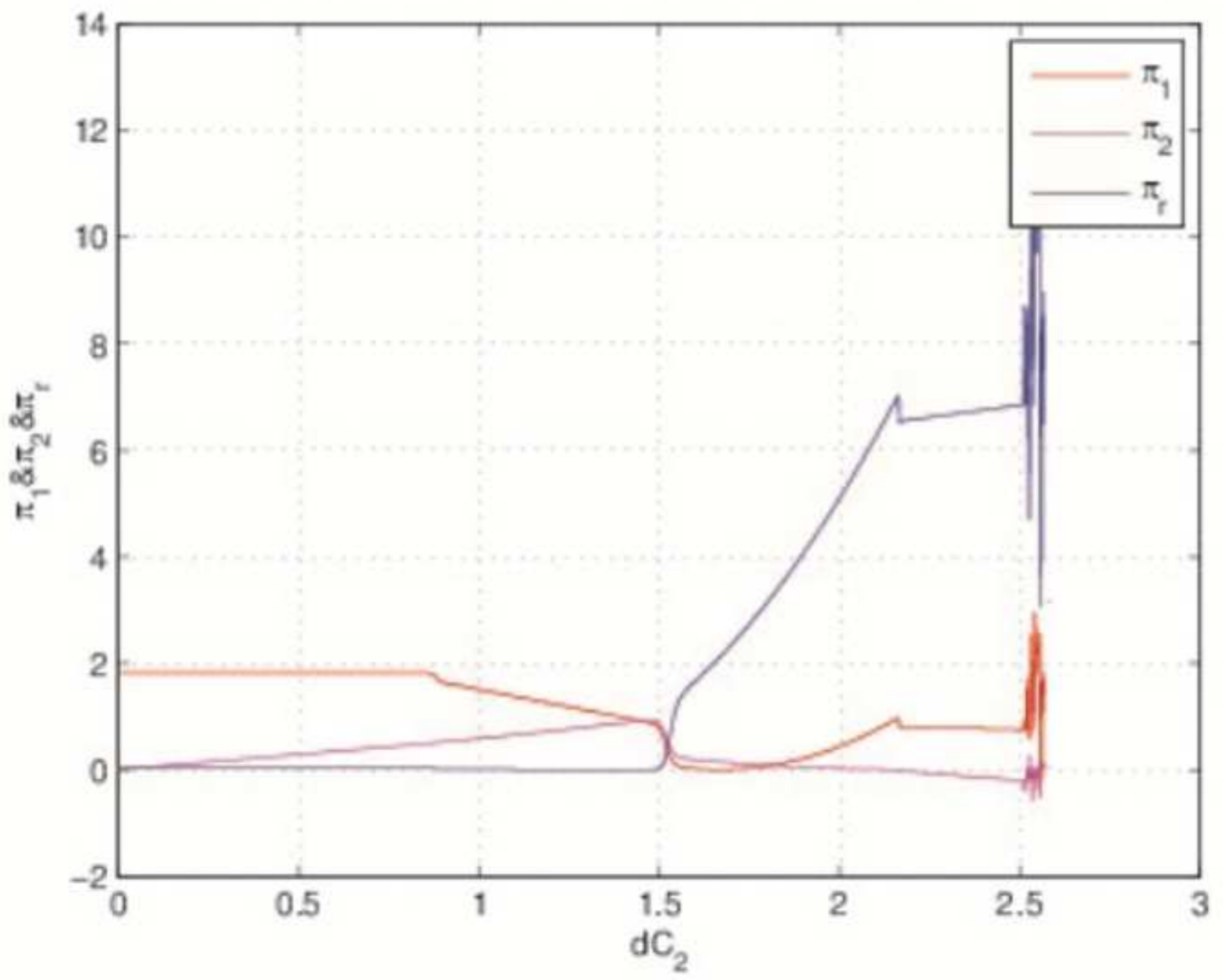

Figure 15

Profit with respect to $\mathrm{dC} 2$ when $\mathrm{v} 1=0.3, \mathrm{v} 2=0.5$ 


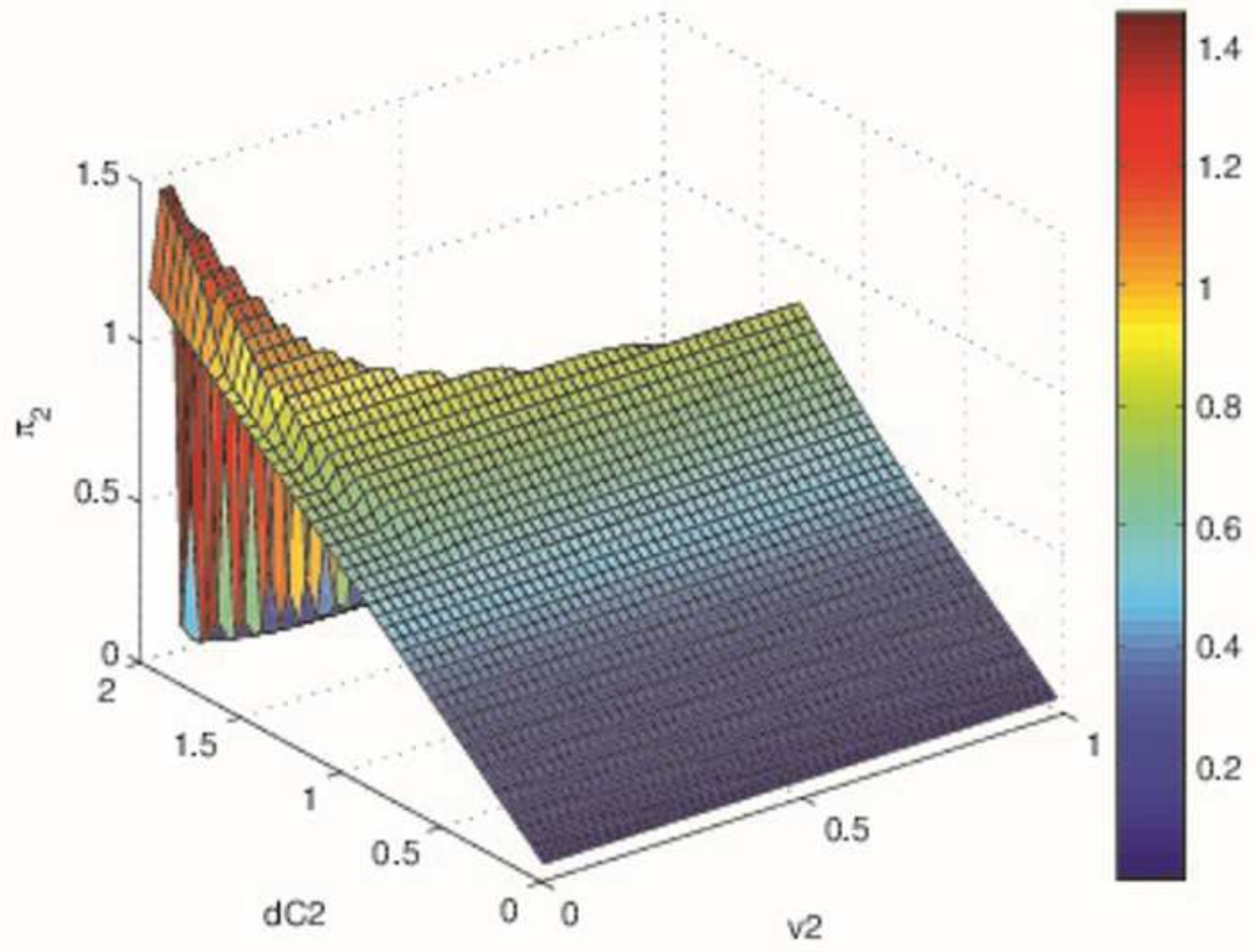

Figure 16

Profit of manufacturer 2 with respect to $\mathrm{v} 2$ and $\mathrm{dC} 2$ 


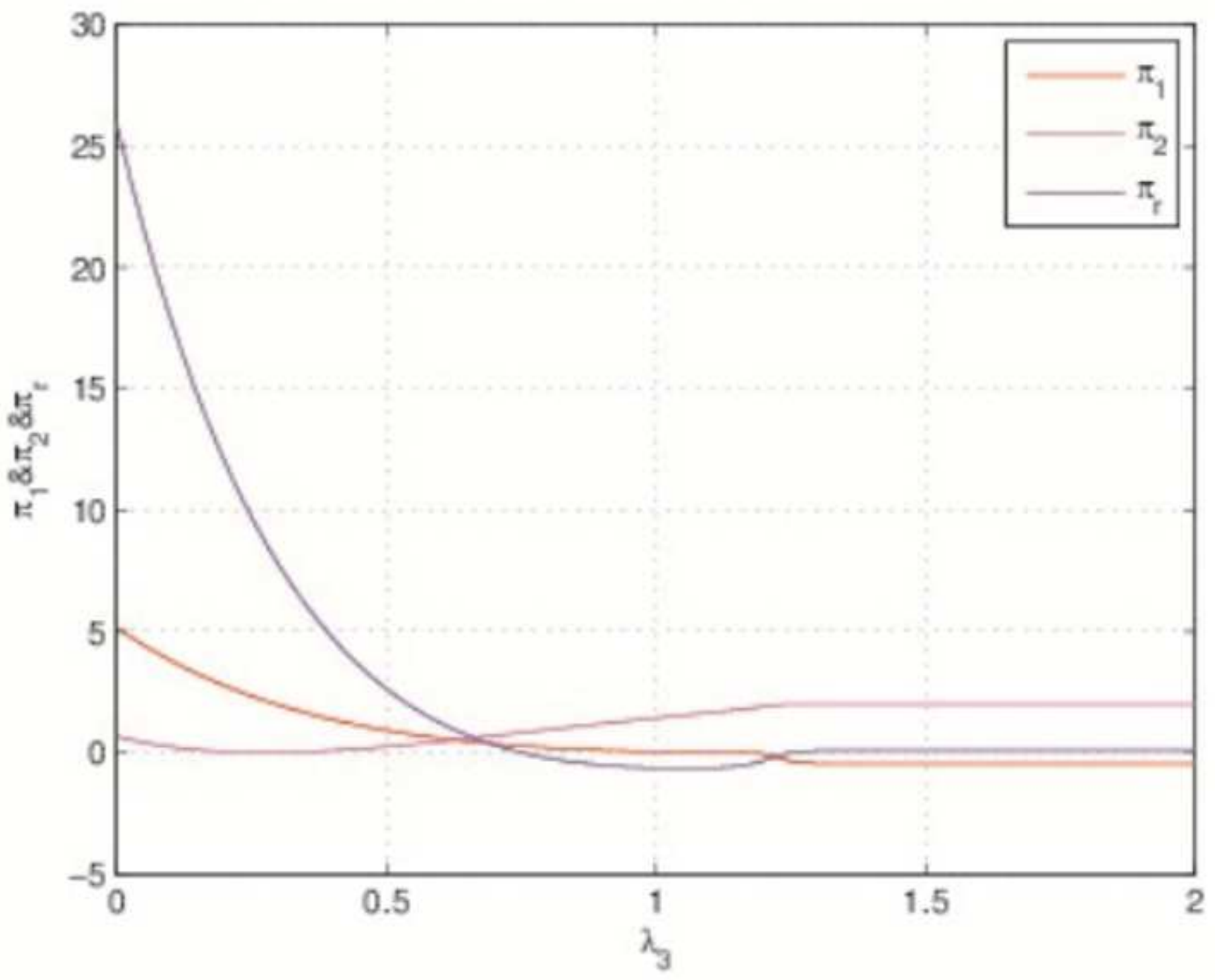

Figure 17

Profit with respect to $\lambda 3$ when $v 1=0.2, v 2=0.2$ 


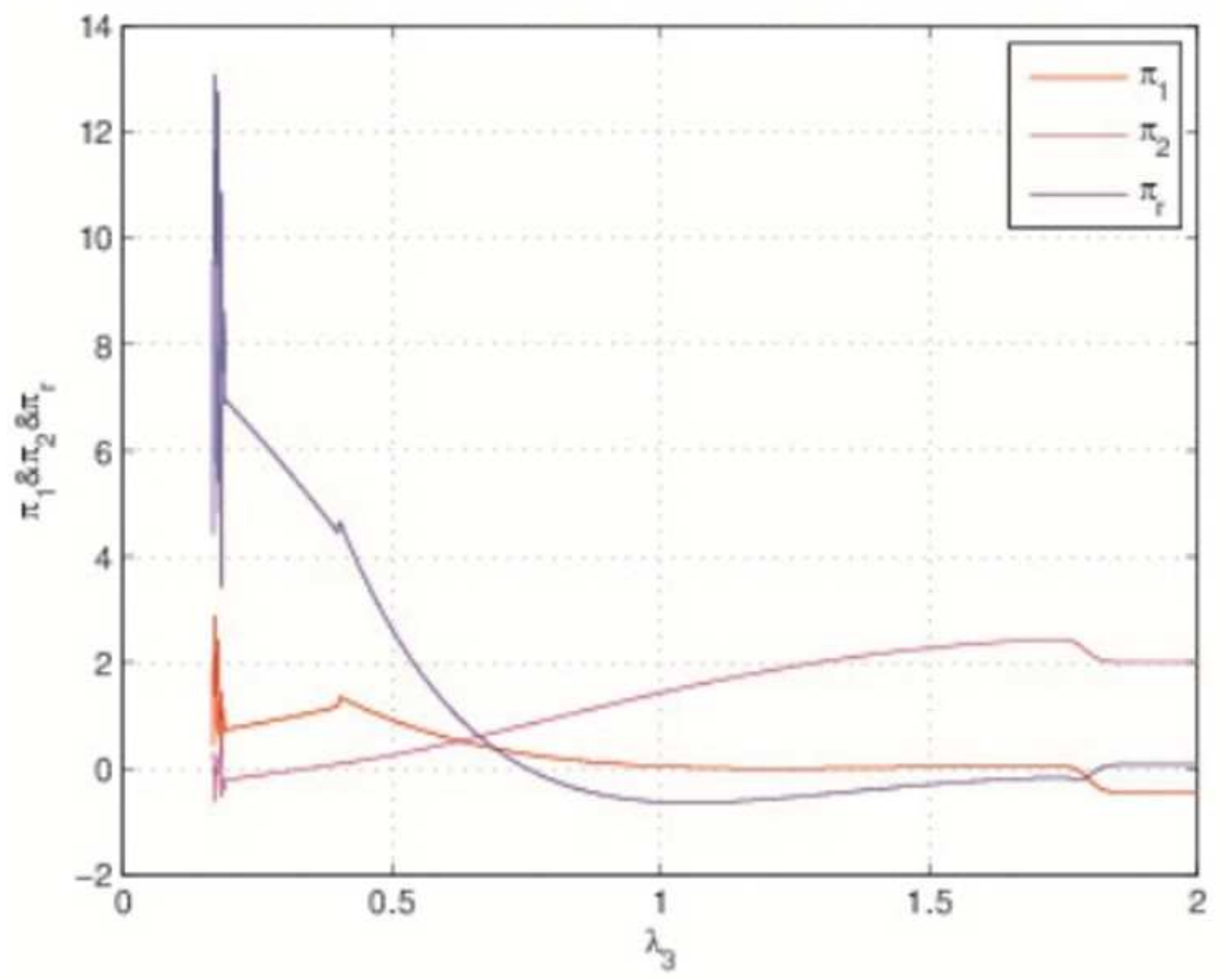

Figure 18

Profit with respect to $\lambda 3$ when $v 1=0.3, v 2=0.5$ 


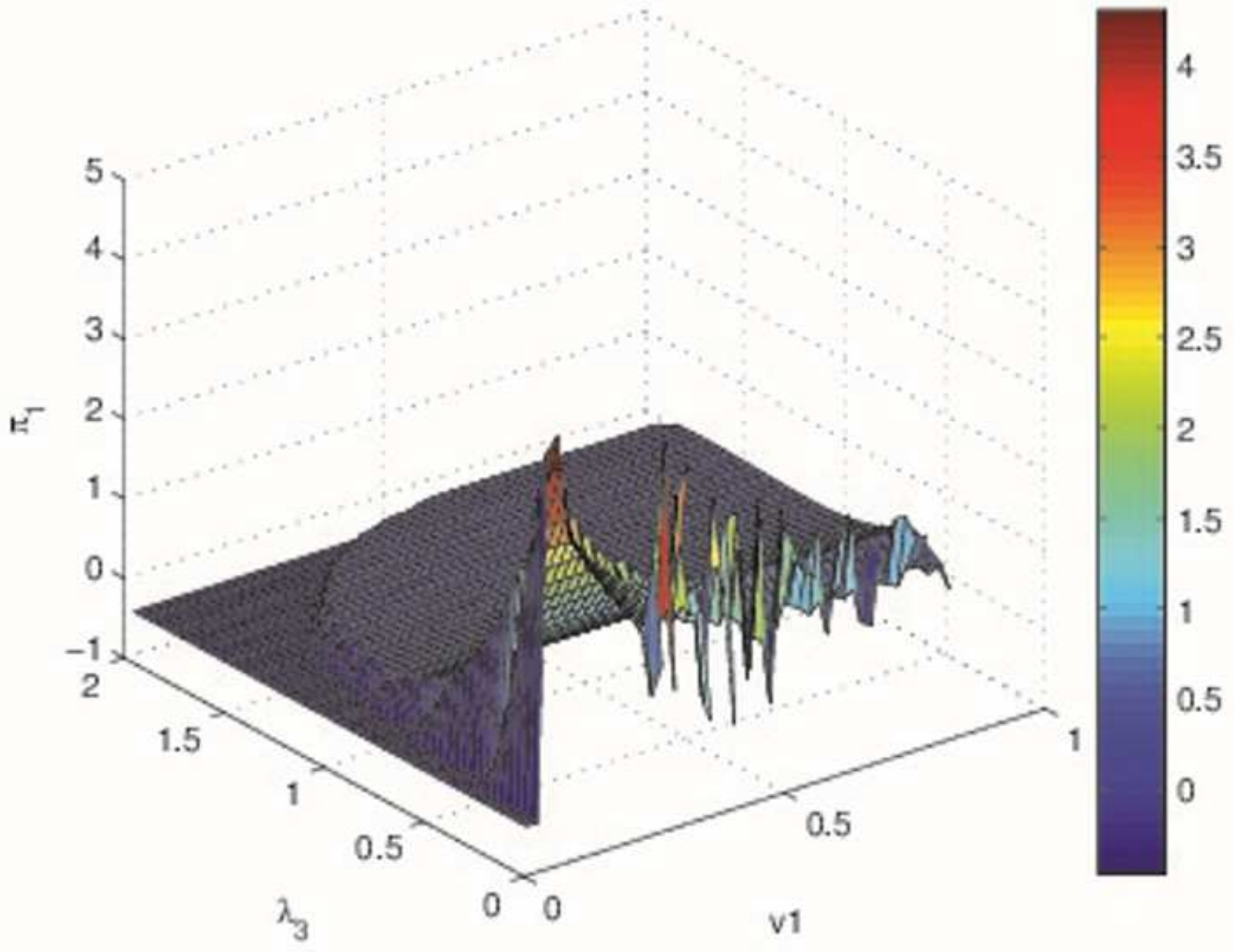

Figure 19

Profit of manufacturer 1 with respect to $\mathrm{v} 1$ and $\lambda 3$ 


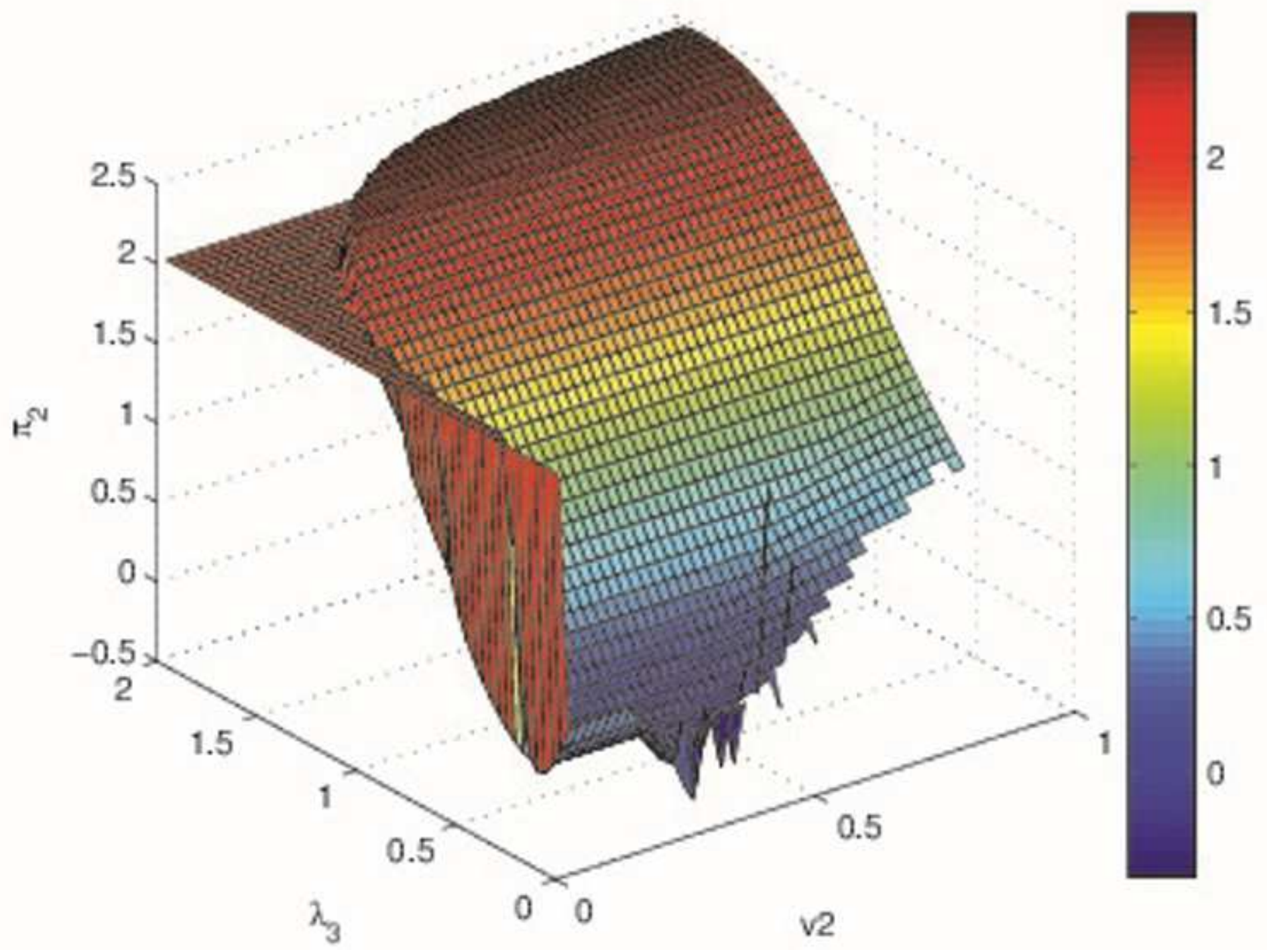

Figure 20

Profit of manufacturer 1 with respect to $\mathrm{v} 2$ and $\lambda 3$ 


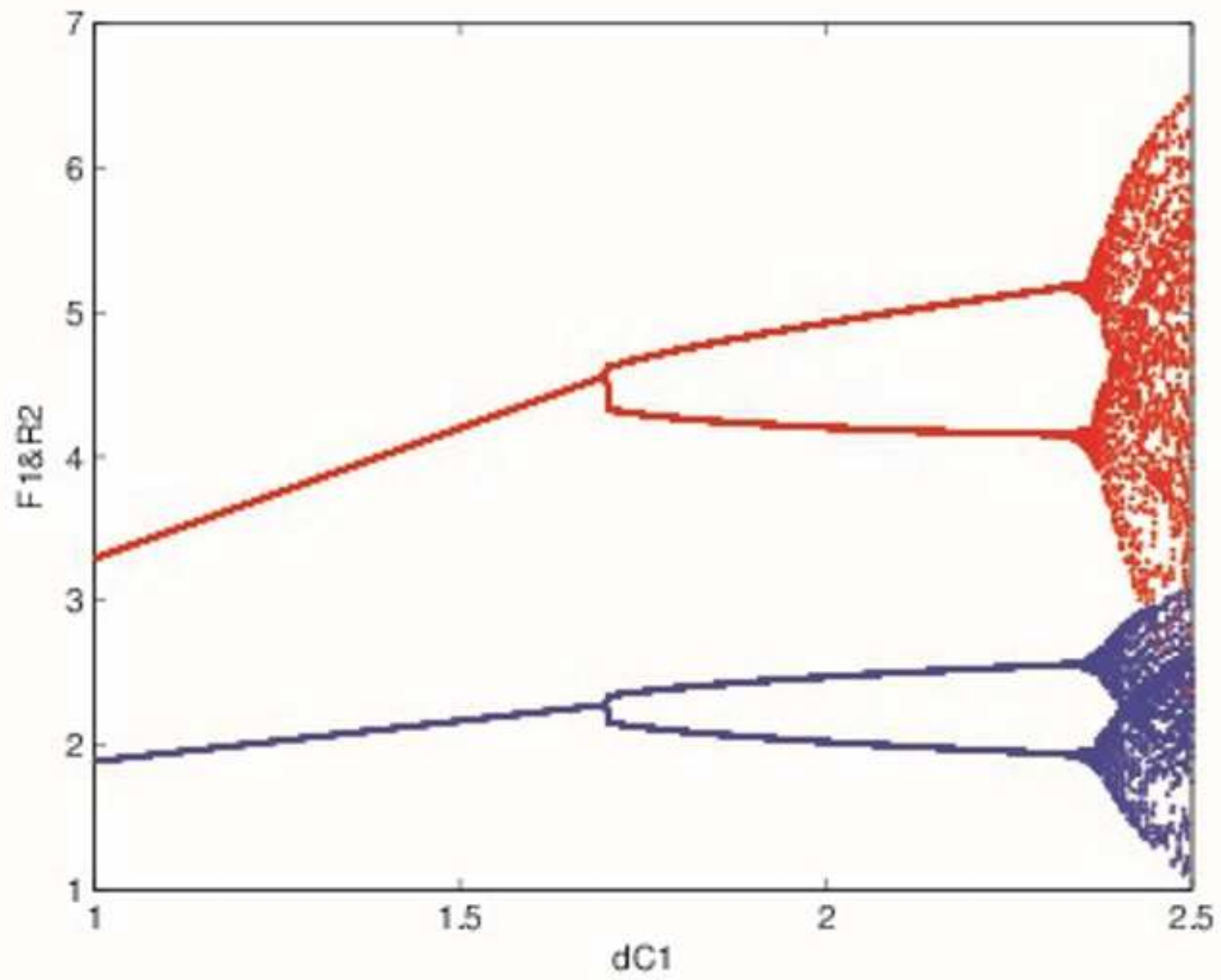

Figure 21

Bifurcation diagram with the change of $d C 1$ when $v 1=0.4, v 2=0.4$ 


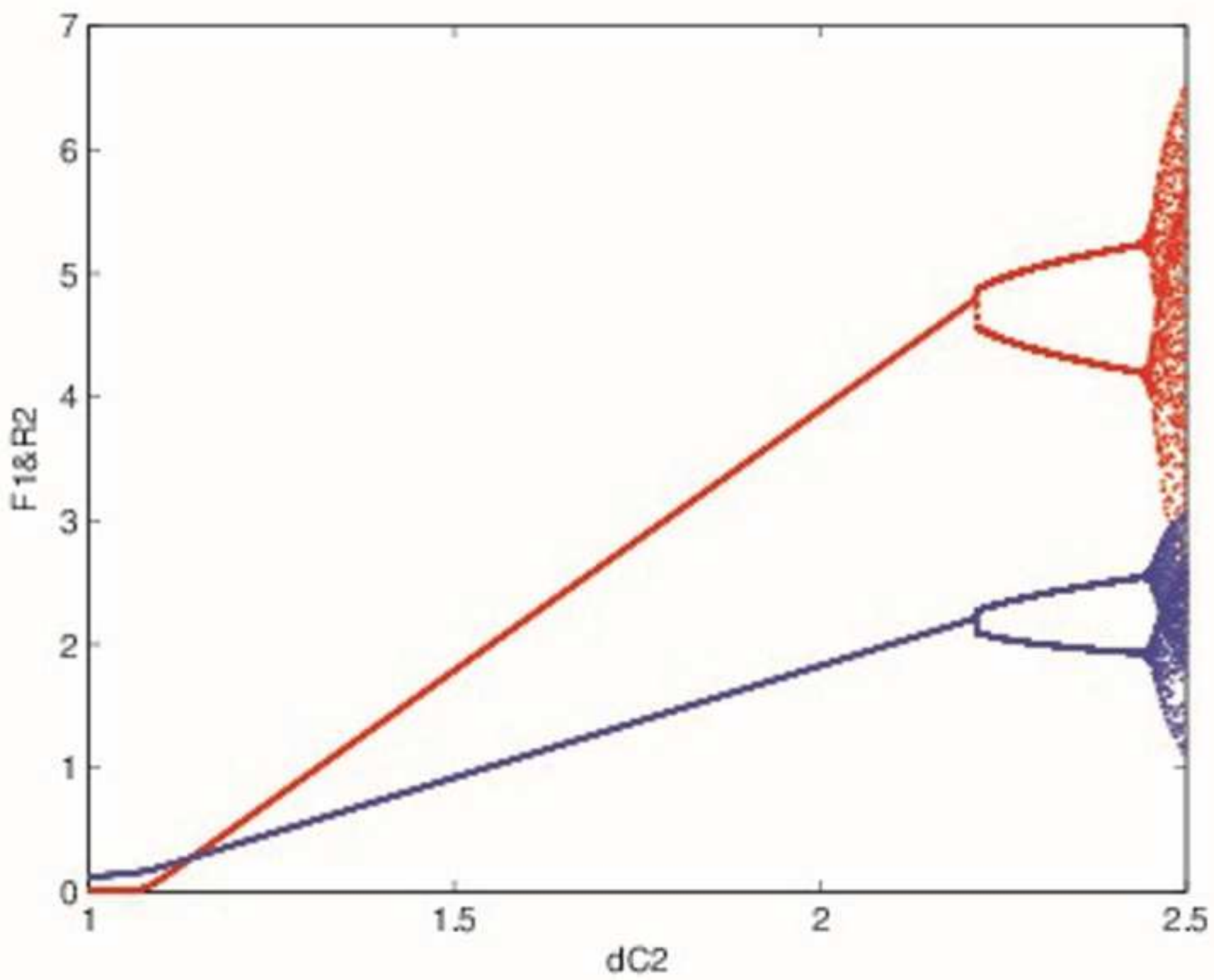

Figure 22

Bifurcation diagram with the change of $d C 2$ when $v 1=0.4, v 2=0.4$ 


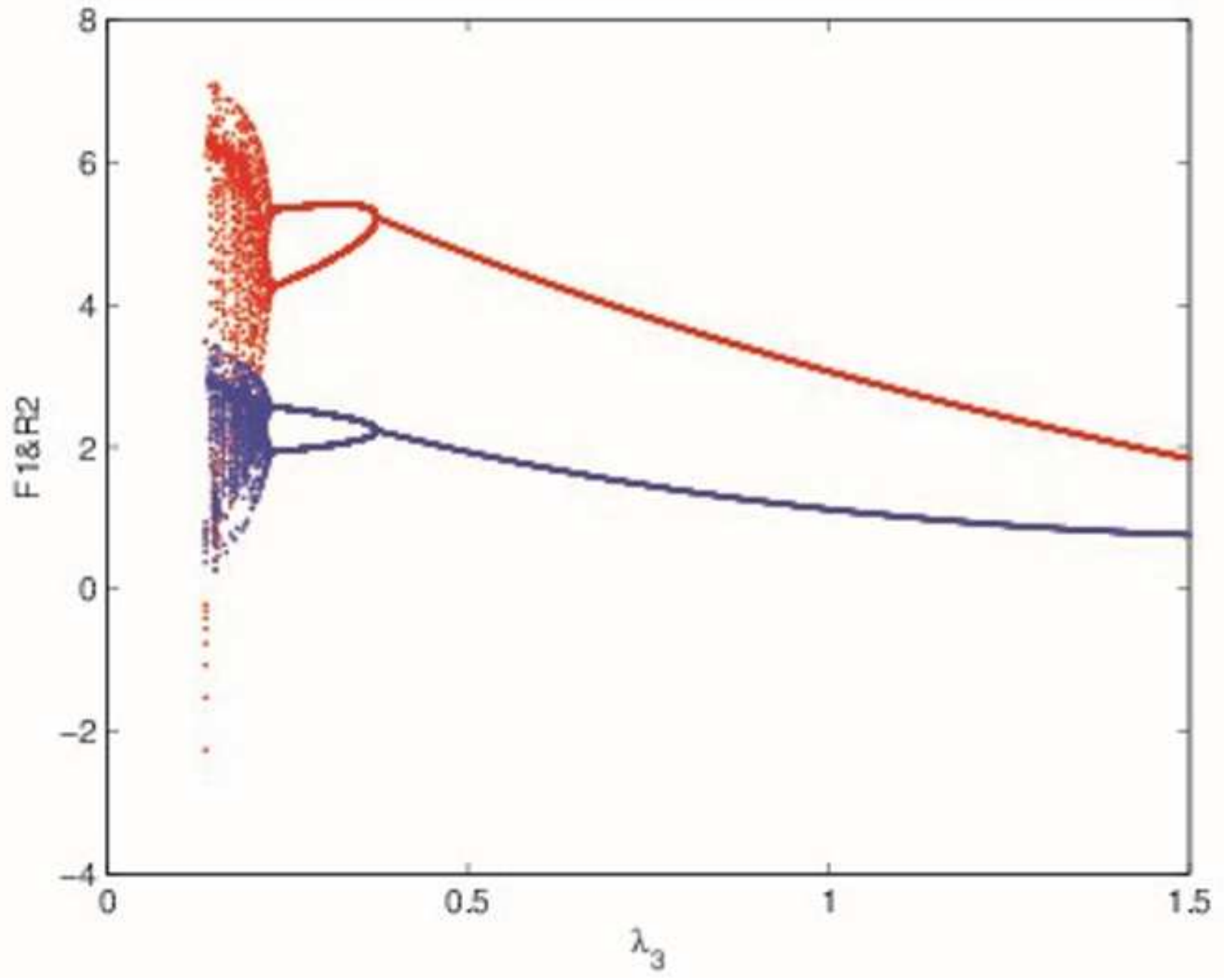

Figure 23

Bifurcation diagram with the change of $\lambda 3$ when $\mathrm{v} 1=0.4, \mathrm{v} 2=0.4$ 


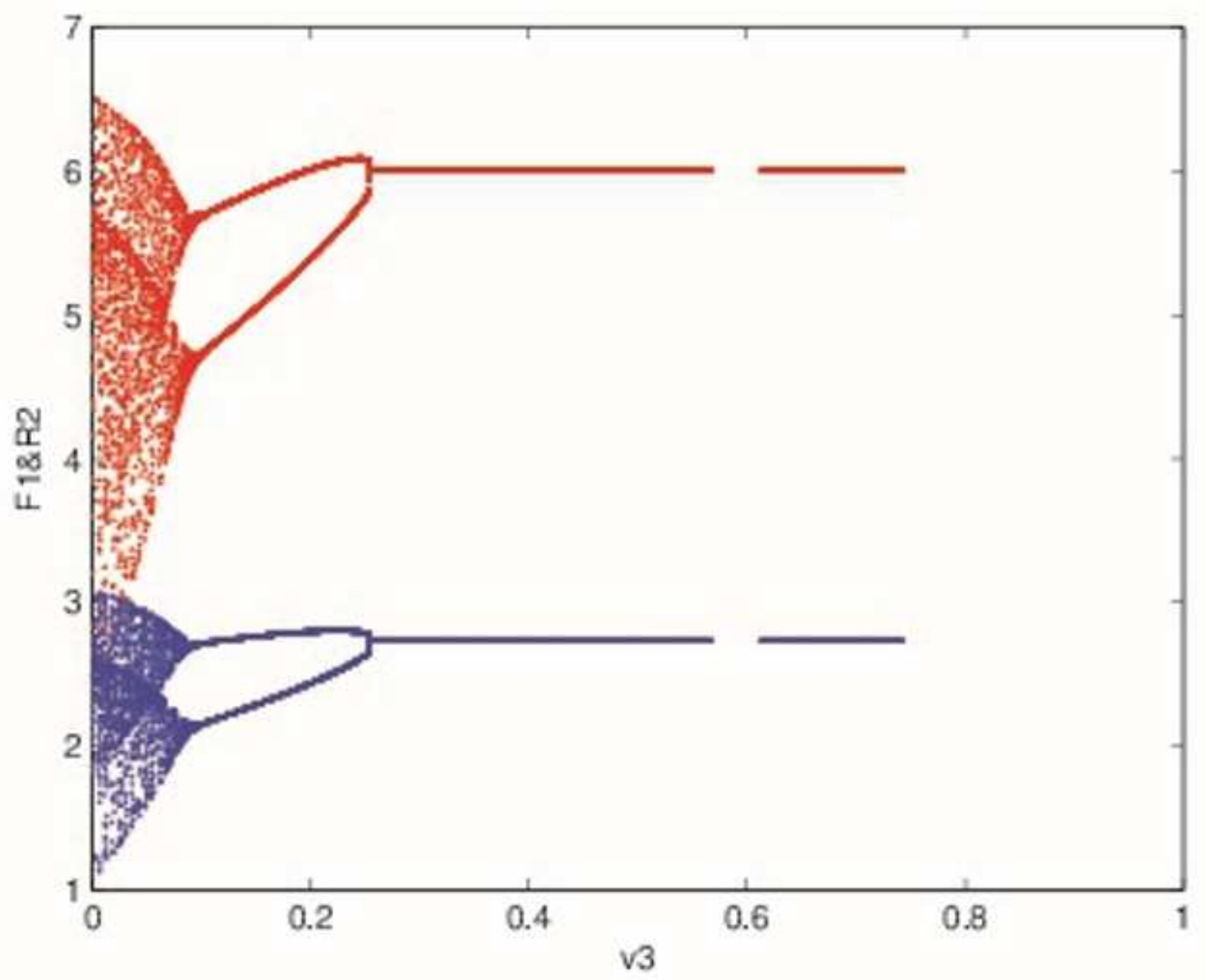

Figure 24

Bifurcation diagram of decision variables with v' increasing 